\title{
Zonas ecológicas de Brosimum alicastrum Sw. en la costa del Pacífico mexicano
}

\author{
Adrián Vega López ${ }^{1}$ \\ Juan Ignacio Valdez Hernández ${ }^{1}$ \\ Víctor Manuel Cetina Alcalá ${ }^{1}$
}

\begin{abstract}
RESUMEN
Se llevó a cabo una revisión de información biofísica existente sobre Brosimum alicastrum Sw. en la costa del Pacífico mexicano, con la finalidad de identificar y caracterizar zonas, de acuerdo con sus principales atributos ecológicos, así como relacionar algunas variables ambientales con la densidad y área basal de esta especie arbórea. Se determinaron 22 zonas ecológicas dentro de cinco tipos de vegetación y fue en la selva mediana subperennifolia donde Brosimum alicastrum presentó su mayor abundancia y desarrollo. La precipitación, altitud y capacidad de almacenamiento de agua en el suelo fueron las variables que mejor explicaron la variación ecológica de la especie en su área de distribución.
\end{abstract}

PALABRAS CLAVE:

Características dasométricas, clima, componentes principales, periodos de crecimiento vegetal, suelo, tipos de vegetación.

\begin{abstract}
A review of biophysical information about Brosimum alicastrum Sw. in the Pacific coast of Mexico was carried out with the purpose of identifing and characterizing zones according to ecological attributes, as well as to relate some environmental variables with density and basal area of this tree species. Twenty two ecological zones were identified in five vegetation types and it was in the semi-evergreen tropical forest where Brosimum alicastrum showed its larger abundance and development. Rainfall, altitude, and water holding capacity of the soil, were the variables that explained better the ecological variation of the species in the area of distribution.
\end{abstract}

KEY WORDS:

Stand characteristics, climate, principal components, plant growth periods, soil, vegetation types. 


\section{INTRODUCCIÓN}

Brosimum alicastrum Sw. es conocido en la costa del Pacífico mexicano como capomo, uje o mojo. Es un árbol característico de las zonas tropicales del continente americano y su área de distribución en México va desde el sur de Sinaloa a Chiapas y del sur de Tamaulipas a la Península de Yucatán. Aunque esta especie tiene un amplio espectro ecológico, su mayor abundancia y desarrollo se presenta en las zonas tropicales húmedas.

Las áreas donde existe Brosimum alicastrum en la costa del Océano Pacífico presentan una gran variabilidad ambiental. Sus condiciones climáticas y edáficas son notablemente diferentes con respecto a las encontradas en regiones tropicales húmedas del Golfo de México y la Península de Yucatán; además, se desconocen las variables ambientales que influyen en la existencia de esta especie en aquella región.

No obstante que Brosimum alicastrum es una de las especies arbóreas más estudiadas en las zonas tropicales, debido principalmente a su gran variedad de usos (madera, forraje, alimento, medicinas), la mayor parte de los estudios se han enfocado a su aprovechamiento y muy pocos a su ecología y conservación (Peters, 1989). Esta situación, motivó la realización del presente trabajo, el cual tuvo como propósito analizar las características ecológicas donde crece Brosimum alicastrum en la costa del Pacífico mexicano.

\section{OBJETIVOS}

- Identificar, con base en las condiciones físicas y atributos biológicos de 55 sitios evaluados, las diferentes zonas ecológicas donde se desarrolla Brosimum alicastrum Sw. en la costa del Pacífico mexicano,
- Describir las principales características climáticas, edáficas, de localización y florísticas de las zonas identificadas; y

- Reconocer aquellas variables ambientales que mejor contribuyen a explicar las características de densidad y área basal de Brosimum alicastrum Sw.

\section{METODOLOGÍA}

Se recabó información sobre estudios de vegetación realizados en la costa del Océano Pacífico. Gran parte de esta información se obtuvo de las memorias regionales de coeficientes de agostadero y tipos de vegetación en los estados de Chiapas, Sinaloa, Jalisco, Colima, Michoacán, Durango, Guerrero, Oaxaca y Nayarit, editadas por la COTECOCA (1972, 1975, 1979a, b, c; $1980 \mathrm{a}, \mathrm{b}, \mathrm{c})$; y de programas de manejo forestal elaborados por Millán y Ortega (1999) y por Solís (datos no publicados). Asimismo, se entrevistaron a diversos técnicos que han realizado estudios de vegetación en las mencionadas entidades federativas. Los resultados se resumen en la Tabla 1.

La información comprendió sólo aquellos sitios de productividad forrajera y lugares donde Brosimum alicastrum crece en forma natural, por tipo de vegetación de acuerdo con el sistema de clasificación de Miranda y Hernández (1985). De esta manera se encontró información para 55 sitios en cinco diferentes tipos de vegetación (selvas: mediana subperennifolia, mediana subcaducifolia, alta perennifolia, alta subcaduifolia y palmares). En cada sitio se consideró el promedio e intervalo de variación de las siguientes variables independientes:

1. Fisiográficas: altitud $(\mathrm{m})$, pendiente $(\%)$, rocosidad (\%) y pedregosidad (\%).

2. Edáficas: profundidad del suelo $(\mathrm{cm})$, $\mathrm{pH}$, textura y capacidad de almacena- 
Tabla 1. Tipo de vegetación y superficie donde se tiene registrada la presencia de Brosimum alicastrum Sw. en la costa del Pacífico mexicano

\begin{tabular}{|c|c|c|}
\hline TIPO DE VEGETACIÓN ${ }^{1}$ & SUPERFICIE (ha) & $\begin{array}{l}\text { ÁRBOLES DE } \\
\text { B. alicastrum POR ha }\end{array}$ \\
\hline Selva mediana subperennifolia & 667981 & $20-147$ \\
\hline Selva mediana subcaducifolia & 3757850 & $4-52$ \\
\hline Selva alta perennifolia & 912400 & 20 \\
\hline Selva alta subcaducifolia & 333601 & 4 \\
\hline Palmar & 158294 & menos de 4 \\
\hline Total & 5830126 & \\
\hline
\end{tabular}

miento de agua. Esta variable se determinó con base en estudios agrológicos detallados realizados en la costa del Océano Pacifico por Agrología (1970, 1971, 1972a, b; 1973, 1974; 1975a, b, c; 1977a, b; 1979a, b). En aquellos sitios donde no fue posible obtener datos, dicha variable se estimó con la ecuación 1.

$$
C A A S=P \cdot C R A T
$$

donde:

CAAS = Capacidad de almacenamiento de agua ( $\mathrm{mm}$ )

$P=$ Profundidad del suelo $(\mathrm{cm})$

CRAT $=$ Capacidad de retención de humedad del suelo según su textura ( $\mathrm{mm}$ de agua por $\mathrm{cm}$ de suelo) (Ortiz y Ortiz, 1990).

3. Climáticas: precipitación $(\mathrm{mm})$, duración de la temporada de lluvias (días) y temperatura media $\left({ }^{\circ} \mathrm{C}\right)$.

4. De vegetación: tipo de vegetación, asociación vegetal, sitio de productividad forrajera y superficie original (ha).

5. Agroecológicas: periodo de crecimiento vegetal (días) de acuerdo con la metodología de la FAO (1981).
Las variables respuesta fueron el porcentaje de árboles perennifolios en la época seca del año, así como el número de individuos (densidad) y área basal por hectárea de Brosimum alicastrum.

Los sitios mencionados anteriormente fueron agrupados en zonas ecológicas por medio del método de análisis multivariable conocido como Componentes Principales, el cual determina los componentes más importantes (combinaciones lineales de variables aleatorias) y las variables que generan la mayor variación dentro de los tipos de vegetación. También se realizaron análisis de regresión con las variables respuesta $e$ independientes arriba citadas, considerando una $p \leq 0,05$. Todos estos análisis se llevaron a cabo en el programa S-PLUS 2000 (Mathsoft Inc., 1999).

En cada zona ecológica se determinaron, por sitio, el índice de diferenciación de diversidad de Whittaker ( $\beta w$, ec. 2) y el coeficiente de similitud florística de Jaccard (CJ, ec. 3) (Magurran, 1988).

$$
\beta w=\left(\frac{s}{\alpha}\right)-1
$$

donde: 
$\beta w$ = índice de diferenciación de diversidad

$s=$ número total de especies registradas en el sistema

$\alpha=$ promedio de diversidad de los sitios

Valores cercanos a 0 indican una escasa diferenciación de diversidad de especies entre dos sitios, mientras que aquellos cercanos a 1 denotan una gran diferen-ciación de diversidad.

$$
C J=\frac{j}{a+b-j} \times 100
$$

donde:

$C J=$ coeficiente de similitud florística

$j$ = número de especies que se encuentran en ambos sitios

$a=$ número de especies que se encuentran en el sitio $A$

$b$ = número de especies que se encuentran en el sitio $B$

A medida que los valores se aproximen al $100 \%$, los sitios en comparación presentan mayor semejanza florística.

Con la finalidad de conocer la relación entre las características del suelo y los atributos de la vegetación (densidad, área basal) se realizaron los siguientes análisis: Primero se realizaron análisis de regresión del porcentaje de limo y arcilla, así como de la profundidad del suelo, con su capacidad de almacenamiento de agua. Después, esta última variable se relacionó con la duración del periodo de crecimiento vegetal, bajo la suposición de que a medida que se prolonga dicho periodo, las condiciones ambientales son más favorables para el desarrollo de Brosimum alicastrum. La duración del periodo de crecimiento vegetal se asoció, a su vez, con el porcentaje de árboles perennifolios, así como con el número de individuos y área basal por hectárea de dicha especie. Se efectuaron análisis de varianza (ANVA) para la precipitación, temporada de lluvias, capacidad de almacenamiento de agua en el suelo y periodos de crecimiento vegetal, considerando un diseño completamente al azar, en donde los tratamientos fueron los tipos de vegetación. La separación de medias se llevó a cabo mediante la diferencia mínima significativa (Cochran y Cox, 1965).

Finalmente, y con el propósito de apoyar el análisis de los resultados obtenidos, se elaboró un perfil fisonómico de la vegetación para una área previamente seleccionada del Pacífico mexicano, usando material cartográfico de COTECOCA (1979b; 1980c), así como cartas de isoyetas e isotermas (temperatura media anual) editadas por la SPP (1981).

\section{RESULTADOS Y DISCUSIÓN}

De acuerdo con los estudios realizados por la COTECOCA (1972, 1975, 1979a, b, c; 1980a, b, c) en la costa del Pacífico y por el autor de este documento, se determinó que el área de distribución natural de Brosimum alicastrum fue de 5830126 hectáreas, con presencia en diez estados (Sinaloa, Durango, Nayarit, Jalisco, Colima, Michoacán, Guerrero, Estado de México, Oaxaca y Chiapas) y formando parte de cinco tipos de vegetación (selvas mediana subperennifolia, mediana subcaducifolia, alta perennifolia y alta subcaducifolia y palmar); sin embargo, sólo en los tres primeros tipos de vegetación la especie de interés fue relativamente abundante, como se observa en la Tabla 1.

\section{Tipos de vegetación y zonas ecológicas}

Selva mediana subperennifolia. En la figura 1 se encuentra el diagrama de dispersión de componentes principales, en donde se agrupan los diferentes sitios de este tipo de vegetación en seis zonas ecológicas. Se observa que con dos componentes principales se explica el $92,8 \%$ de la variabilidad total en este tipo de vegetación y que los coeficientes de las variables altitud (V2), precipitación (V9) y, en menor grado, la capacidad de almacenamiento de agua del suelo (V7), son los que contribuyen en mayor medida a explicar la variabilidad de esta especie. La figura 2 señala la ubicación geográfica de los sitios evaluados. 
En la figura 3 se aprecia que Brosimum alicastrum se localiza principalmente en aquellos sitios donde las condiciones edáficas ofrecen a las plantas una mayor disponibilidad de agua a lo largo del año. Esta especie parece ser demandante de este líquido, ya que la mayor parte de los suelos donde se desarrolla son profundos y con alta capacidad para su almacenamiento o están sujetos a la acumulación de humedad residual proveniente de escurrimientos de las partes altas y a la infiltración, así como de otras fuentes permanentes de agua. También se presenta en sitios con alta humedad ambiental, como barrancas protegidas o zonas expuestas a la brisa marina.

La Tabla 2 muestra que el $98,4 \%$ de la superficie ocupada por las zonas ecológicas de Brosimum alicastrum se encuentra por abajo de los 400 msnm, con sólo una pequeña superficie por arriba de los 600 msnm. Vega (no publicado) describe la existencia de comunidades reliquia de esta especie en el sur del Estado de México, donde se ha registrado a su máxima altitud ( $1050 \mathrm{~m}$ ) en forma natural, en una región localizada fuera del área de distribución natural de esta especie.

Las zonas ecológicas de Brosimum alicastrum en la selva mediana subperennifolia poseen una moderada diferenciación de diversidad de especies arbóreas entre sitios y una baja similitud florística entre ellos (Tabla 2). Asimismo, la especie de interés presenta su mayor abundancia en este tipo de vegetación: hasta 147 árboles por hectárea fueron registrados en Nayarit (Solís, datos no publicados) y el Estado de México (Tabla 1).

De acuerdo con COTECOCA (1975, 1979 a, b; 1980 a, b, c) y Vega (1989), el $82,2 \%$ de la superficie original que ocuparon las zonas ecológicas de Brosimum alicastrum en la costa del Pacífico se encontró entre las isoyetas de $600 \mathrm{~mm}$ a $1200 \mathrm{~mm}$ anuales, siendo el nivel más bajo registrado para esta especie en el país.

Selva mediana subcaducifolia. En la figura 4 se encuentra el diagrama de dispersión de componentes principales, en donde se agrupan los diferentes sitios que integran este tipo de vegetación en cinco zonas ecológicas. Se observa que con dos componentes principales se explica el $98,5 \%$ de la variabilidad global en este tipo de vegetación y que los coeficientes de las variables altitud (V2) y precipitación (V9) son los que contribuyen en mayor medida a explicar dicha proporción de la variabilidad. La figura 2 muestra la ubicación de los sitios evaluados.

En la Tabla 2 se describen las principales características de las zonas ecológicas de Brosimum alicastrum, que se agruparon con base en el diagrama de la figura 4 (componentes principales), para la selva mediana subcaducifolia la cual, de acuerdo con los estudios realizados por COTECOCA (1975, 1979a, b, c; 1980a, b, c), fue el tipo de vegetación más ampliamente distribuido en la costa del Pacífico (3 757850 ha).

En la figura 3 se aprecia que este tipo de vegetación colinda, en su límite altitudinal inferior, con la selva mediana subperennifolia y el palmar, así como en el límite altitudinal superior, con el bosque de encinos, ocupando lomeríos y terrenos cerriles con suelos de profundidad de somera a media $(0 \mathrm{~cm}$ a $50 \mathrm{~cm})$, textura gruesa y baja capacidad de retención de agua.

En la selva mediana subcaducifolia, Brosimum alicastrum se considera como una especie arbórea codominante, encontrándose en las zonas más húmedas y en ecotonos con la selva mediana subperennifolia, presentando un menor desarrollo estructural comparado con este último tipo de vegetación e incluso puede tirar su follaje en los sitios más secos, como una adaptación al estrés hídrico (COTECOCA, 1975, 1979a, b, c; 1980a, b, c; Millán y Ortega, 1999; Solís, datos no publicados). 


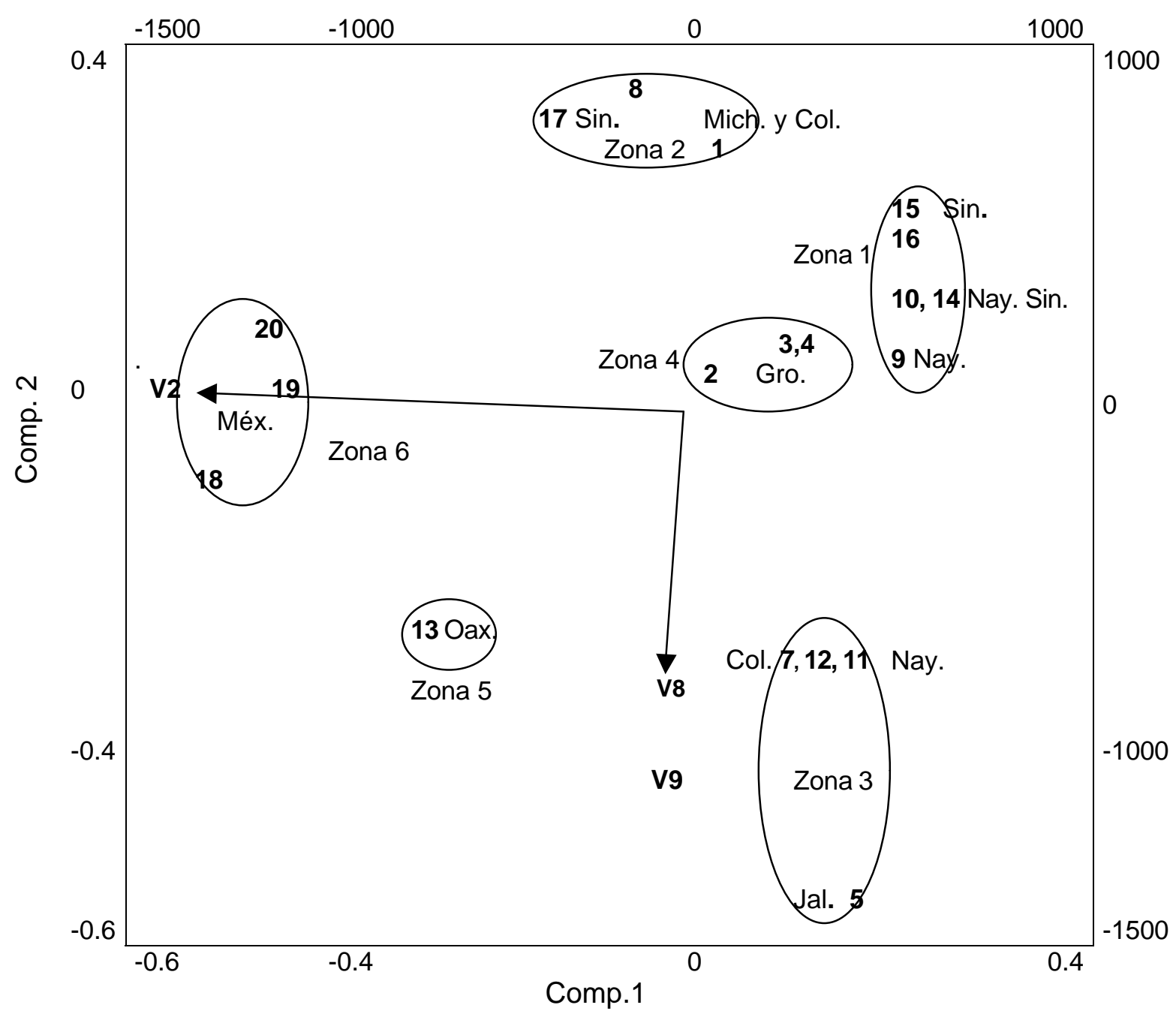

\begin{tabular}{ccl}
\hline $\begin{array}{c}\text { Componente } \\
\text { principal }\end{array}$ & $\begin{array}{c}\text { Importancia } \\
\text { relativa }\end{array}$ & \multicolumn{1}{c}{ Combinación lineal * $^{*}$} \\
\hline 1 & 0,586 & $Y_{1}=-0,993 \mathrm{~V} 2$ \\
\hline 2 & 0,928 & $Y_{2}=-0,998 \mathrm{~V} 9$ \\
\hline 3 & 0,991 & $Y_{3}=0,104 \mathrm{~V} 2+0,201 \mathrm{~V} 6+0,859 \mathrm{~V} 7+0,449 \mathrm{~V} 11$ \\
\hline
\end{tabular}

*V2,altitud; V6, profundidad de suelo; V7, capacidad de almacenamiento de agua en el suelo; V9, precipitación; $\mathrm{V} 11$, periodo de crecimiento vegetal.

Figura 1. Agrupamiento en zonas ecológicas de los diferentes sitios de selvas medianas subperennifolias en la costa del Océano Pacífico.

Sitios de los estados de: Guerrero (2 - 4), Jalisco (5 -7), Michoacán y Colima (1 y 8), Nayarit (9 - 12), Oaxaca (13), Sinaloa (14 - 17) y México (18 - 20), (Tabla 2 y Fig. 2) 

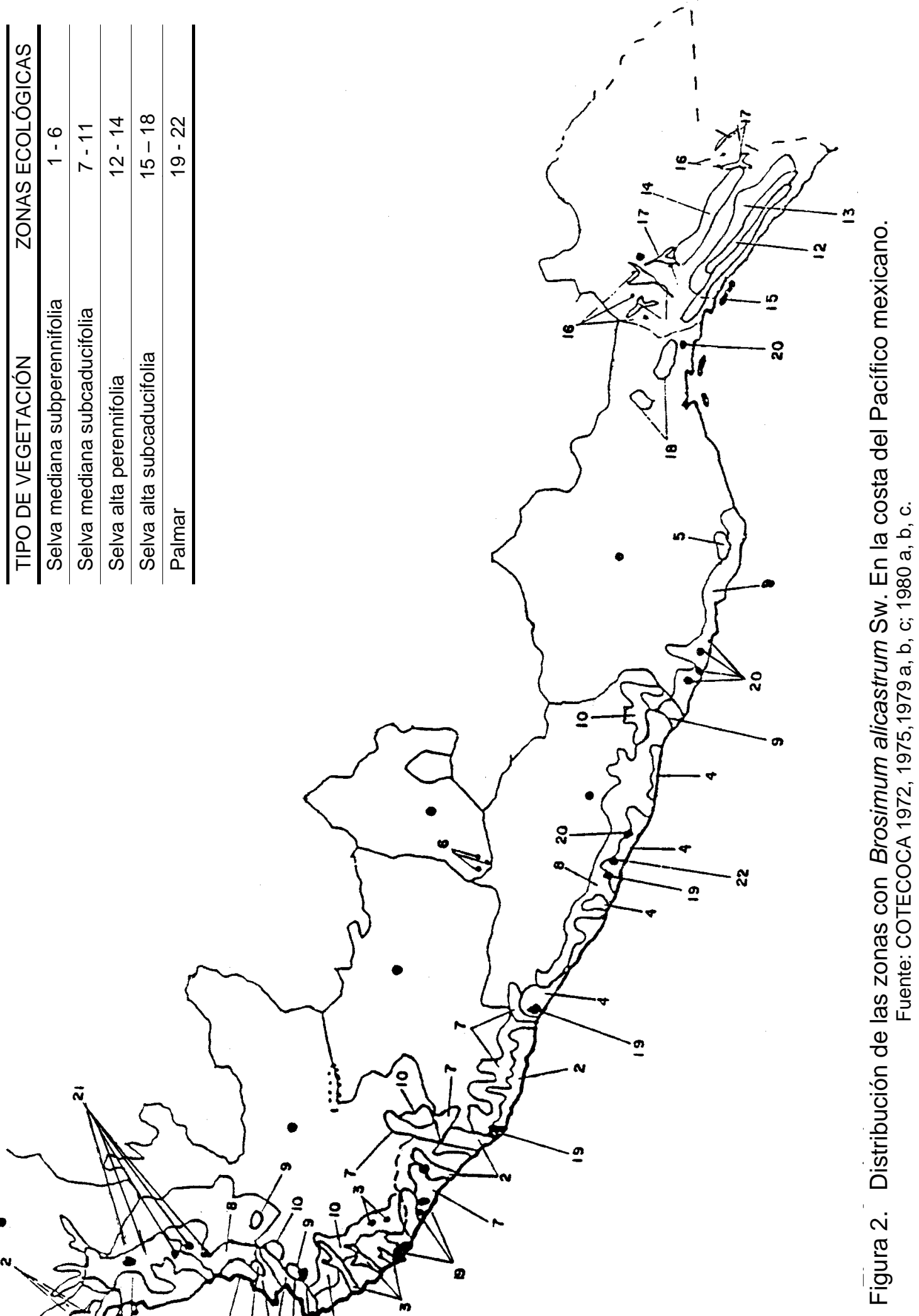


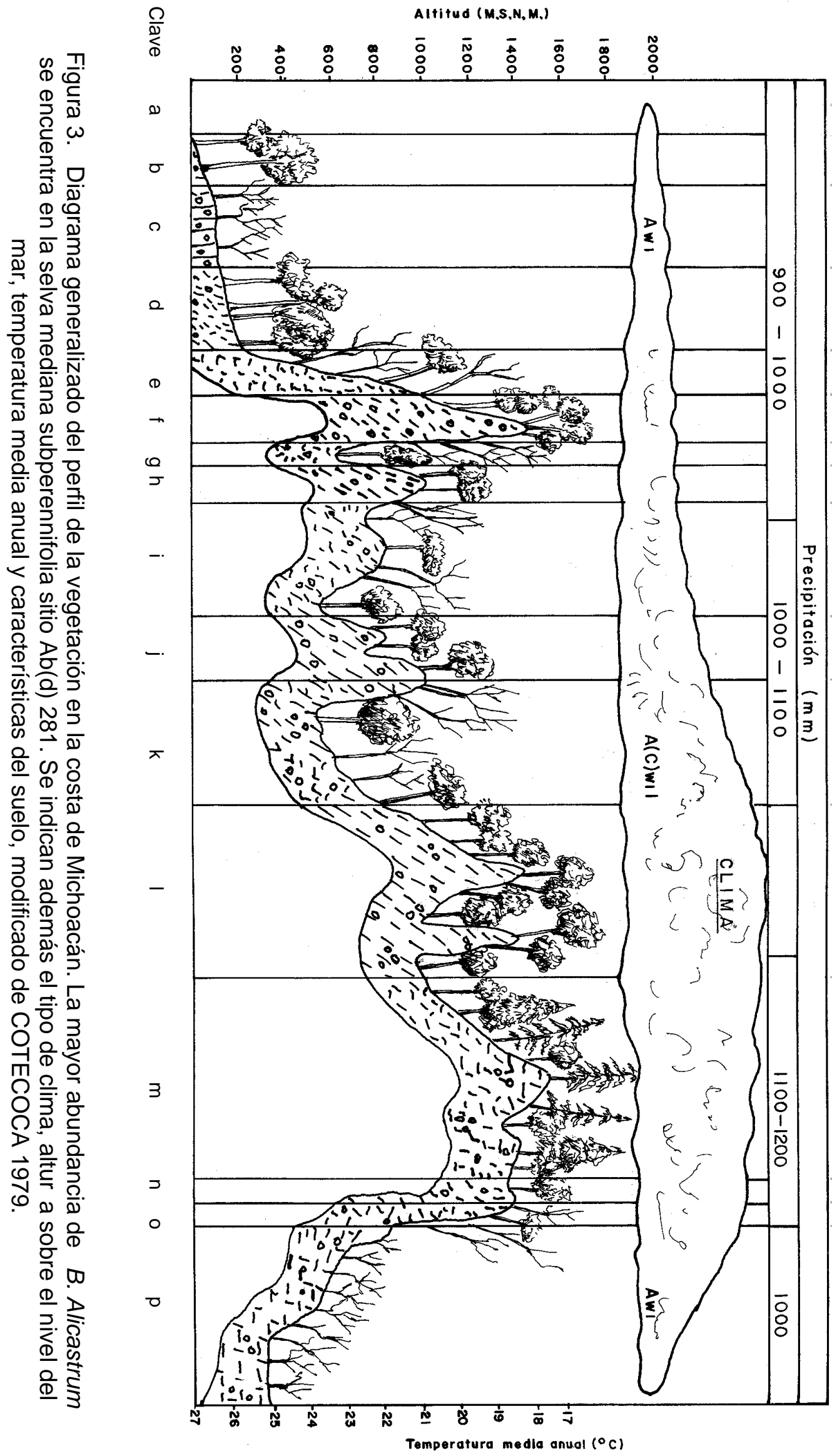


Figura 3 (cont...). Nomenclatura

\begin{tabular}{|c|c|c|c|}
\hline Clave & Características del suelo & Tipo de vegetación & Clave de sitio \\
\hline $\bar{a}$ & & & Mar \\
\hline $\mathrm{b}$ & $\begin{array}{l}\text { aluvial y coluvial, somero a } \\
\text { profundo areno limoso y } \\
\text { arcilloso }\end{array}$ & $\begin{array}{l}\text { Selva mediana } \\
\text { subperennifolia }\end{array}$ & $A b(d) 281$ \\
\hline c & $\begin{array}{l}\text { aluvial, profundo, franco } \\
\text { arcilloso }\end{array}$ & $\begin{array}{l}\text { Selva baja caducifolia } \\
\text { espinosa }\end{array}$ & Acek 281 \\
\hline d & $\begin{array}{l}\text { insitu, aluvial y coluvial, } \\
\text { somero a profundo, areno } \\
\text { limoso y arcilloso }\end{array}$ & $\begin{array}{l}\text { Selva Mediana } \\
\text { subperennifolia }\end{array}$ & Abd 281 \\
\hline e & $\begin{array}{l}\text { insitu y coluvial, medio a } \\
\text { somero, areno arcilloso y } \\
\text { franco arenoso }\end{array}$ & $\begin{array}{l}\text { Selva mediana } \\
\text { subperennifolia }\end{array}$ & $\mathrm{Ab}(\mathrm{e}) 282$ \\
\hline$f$ & $\begin{array}{l}\text { insitu y coluvial, somero } \\
\text { areno arcilloso y arcilloso }\end{array}$ & Bosque de encinos & Bfe 282 \\
\hline g & $\begin{array}{l}\text { insitu y coluvial, somero a } \\
\text { medio areno arcilloso }\end{array}$ & & $\mathrm{Ab}(\mathrm{e}) 286$ \\
\hline $\mathrm{h}$ & $\begin{array}{l}\text { insitu y coluvial, somero } \\
\text { areno arcilloso }\end{array}$ & Bosque de encinos & Bfe 282 \\
\hline $\mathrm{i}$ & $\begin{array}{l}\text { insitu y coluvial, somero a } \\
\text { medio, areno arcilloso y } \\
\text { franco arenoso }\end{array}$ & $\begin{array}{l}\text { Selva mediana } \\
\text { subcaducifolia }\end{array}$ & $\mathrm{Ab}(\mathrm{e}) 282$ \\
\hline j & $\begin{array}{l}\text { insitu y coluvial somero } \\
\text { areno arcilloso y arcilloso }\end{array}$ & Bosque de encinos & Bfe 282 \\
\hline $\mathrm{k}$ & $\begin{array}{l}\text { insitu y coluvial medio a } \\
\text { somero, areno arcilloso y } \\
\text { franco arenoso }\end{array}$ & $\begin{array}{l}\text { Selva mediana } \\
\text { subcaducifolia }\end{array}$ & $A b(e) 282$ \\
\hline I & $\begin{array}{l}\text { insitu y coluvial somero } \\
\text { areno arcilloso y arcilloso }\end{array}$ & Bosque de encinos & Bfe 282 \\
\hline $\mathrm{m}$ & $\begin{array}{l}\text { insitu, medio a profundo, } \\
\text { arcillo arenoso }\end{array}$ & Bosque de encinos & Bjf 283 \\
\hline $\mathrm{n}$ & $\begin{array}{l}\text { insitu, somero, areno } \\
\text { arcilloso y arcilloso }\end{array}$ & & Bfe 282 \\
\hline 0 & $\begin{array}{l}\text { insitu y coluvial somero a } \\
\text { medio areno arcilloso }\end{array}$ & & $A b(e) 283$ \\
\hline $\mathrm{p}$ & $\begin{array}{l}\text { coluvial, somero a medio } \\
\text { arcillo arenoso }\end{array}$ & Selva baja caducifolia & Ace 281 \\
\hline
\end{tabular}


Tabla 2. Características ecológicas de las zonas con Brosimum alicastrum Sw. en la costa del Océano Pacífico por tipo de vegetación (Fig. 1, 2 y 4 a 7)

\begin{tabular}{|c|c|c|c|c|c|c|}
\hline \multirow{2}{*}{ Característica } & \multicolumn{6}{|c|}{ Selva mediana subperennifolia } \\
\hline & Zona 1 & Zona 2 & Zona 3 & Zona 4 & Zona 5 & Zona 6 \\
\hline $\begin{array}{l}\text { Localización: } \\
\text { Entidad y No. de } \\
\text { sitio }\end{array}$ & $\begin{array}{l}\text { Nayarit } \\
(9 \text { y 10) y } \\
\text { Sinaloa } \\
(14-16)\end{array}$ & $\begin{array}{c}\text { Michoacán y } \\
\text { Colima } \\
(1 \text { y } 8) \\
\text { Sinaloa (17) }\end{array}$ & $\begin{array}{c}\text { Jalisco } \\
(5-7) \\
\text { Nayarit } \\
(11 \text { y } 12)\end{array}$ & $\begin{array}{c}\text { Guerrero } \\
(2-4)\end{array}$ & $\begin{array}{c}\text { Oaxaca } \\
(13)\end{array}$ & $\begin{array}{l}\text { México } \\
(18-20)\end{array}$ \\
\hline Superficie (ha) & 223137 & 57713 & 146423 & 225170 & 15528 & 10 \\
\hline Fisiografía & $\begin{array}{c}\text { planos } \\
\text { dunas y } \\
\text { vegas de río }\end{array}$ & $\begin{array}{l}\text { planos } \\
\text { aluviales } \\
\text { cañadas y } \\
\text { cerros }\end{array}$ & $\begin{array}{l}\text { planos } \\
\text { valles } \\
\text { cañadas y } \\
\text { cerros }\end{array}$ & $\begin{array}{l}\text { planos } \\
\text { lomeríos } \\
\text { y cerros }\end{array}$ & cerros & cañadas \\
\hline Altitud (m) & $26-75$ & $310-525$ & $102-350$ & $200-300$ & 650 & $875-1050$ \\
\hline Pendiente (\%) & $2,0-2,5$ & $3-50$ & $2-40$ & $11,5-45$ & 18 & $38-55$ \\
\hline Rocosidad (\%) & 0 & $1,5-40$ & $0-11,5$ & $0-15$ & --- & $1,7-15$ \\
\hline $\begin{array}{l}\text { Pedregosidad } \\
(\%)\end{array}$ & $0-5,5$ & $0-30$ & $0-22,5$ & $0-12,5$ & --- & $2,5-70$ \\
\hline $\begin{array}{l}\text { Profundidad del } \\
\text { suelo }(\mathrm{cm})\end{array}$ & 100 & $50-100$ & $25-100$ & 75 & 37,5 & $25-150$ \\
\hline $\begin{array}{l}\text { Capacidad de } \\
\text { almacenamiento } \\
\text { de agua en el } \\
\text { suelo }(\mathrm{mm})\end{array}$ & $176-436$ & $191-221$ & $87-326$ & $95-175$ & 53 & $40-251$ \\
\hline $\mathrm{pH}$ del suelo & 5,5 & $6,6-6,7$ & $6,3-6,6$ & $5,0-5,5$ & 5,4 & 6,6 \\
\hline $\begin{array}{l}\text { Precipitación } \\
\text { media }(\mathrm{mm})\end{array}$ & $1000-1150$ & $900-950$ & $1500-1750$ & $1150-1200$ & 1500 & $1200-1350$ \\
\hline $\begin{array}{l}\text { Temporada de } \\
\text { lluvias (días) }\end{array}$ & $121-140$ & $121-160$ & $150-169$ & $143-174$ & 148 & $152-165$ \\
\hline $\begin{array}{l}\text { Periodo de } \\
\text { crecimiento } \\
\text { vegetal (días) }\end{array}$ & $197-365$ & $161-234$ & $194-301$ & $189-208$ & 171 & $163-293$ \\
\hline $\begin{array}{l}\text { Temperatura } \\
\text { media }\left({ }^{\circ} \mathrm{C}\right)\end{array}$ & $25-26$ & $25-29$ & $24-26$ & $26-27$ & 22 & $23,0-24,5$ \\
\hline $\begin{array}{l}\text { Especies } \\
\text { características }\end{array}$ & $\begin{array}{l}\text { B. alicastrum } \\
\text { E.cyclocarpum } \\
\text { Ficus spp. }\end{array}$ & $\begin{array}{l}\text { B. alicastrum } \\
\text { H. polyandra } \\
\text { R.donell smith }\end{array}$ & $\begin{array}{l}\text { B. alicastrum } \\
\text { E.cyclocarpum } \\
\text { H. polyandra }\end{array}$ & $\begin{array}{l}\text { A. graveolens } \\
\text { B. alicastrum } \\
\text { B. simaruba }\end{array}$ & $\begin{array}{l}\text { P.acapulcencis } \\
\text { C.candidissimum }\end{array}$ & $\begin{array}{l}\text { B.alicastrum } \\
\text { L.arborea } \\
\text { F.padifolia }\end{array}$ \\
\hline $\begin{array}{l}\text { Índice promedio } \\
\text { de diferenciación } \\
\text { de diversidad } \\
\text { entre sitios }\end{array}$ & 0,62 & 0,53 & 0,50 & 0,57 & --- & 0,50 \\
\hline $\begin{array}{l}\text { Índice promedio } \\
\text { de similitud } \\
\text { florística entre } \\
\text { sitios }\end{array}$ & 24,0 & 38,7 & 42,4 & 26,1 & --- & 34,0 \\
\hline $\begin{array}{l}\text { No. de especies } \\
\text { arbóreas } \\
\text { registradas } \\
\end{array}$ & 28 & 31 & 28 & 43 & 19 & 19 \\
\hline
\end{tabular}


Tabla 2 (cont...). Características ecológicas de las zonas con Brosimum alicastrum Sw. en la costa del Océano Pacífico por tipo de vegetación

\begin{tabular}{|c|c|c|c|c|c|}
\hline \multirow{2}{*}{ Característica } & \multicolumn{5}{|c|}{ Selva mediana subcaducifolia } \\
\hline & Zona 7 & Zona 8 & Zona 9 & Zona 10 & Zona 11 \\
\hline $\begin{array}{l}\text { Localización: } \\
\text { Entidad y No. de } \\
\text { sitio }\end{array}$ & $\begin{array}{c}\text { Guerrero (4), } \\
\text { Jalisco (8), } \\
\text { Michoacán y } \\
\text { Colima (1 y 2) }\end{array}$ & $\begin{array}{l}\text { Guerrero } \\
\text { (6 y } 7) \text { y } \\
\text { Nayarit (14) }\end{array}$ & $\begin{array}{c}\text { Guerrero (3), } \\
\text { Oaxaca (16 y 17), } \\
\text { Jalisco (9), } \\
\text { Nayarit y Duran- } \\
\text { go }(11,12 \text { y } 15)\end{array}$ & $\begin{array}{c}\text { Guerrero (5), } \\
\text { Jalisco (10) y } \\
\text { Nayarit (13) }\end{array}$ & Sinaloa (18) \\
\hline Superficie (ha) & 457616 & 946897 & 1336527 & 732932 & 283878 \\
\hline Fisiografía & $\begin{array}{l}\text { planos, } \\
\text { lomeríos y } \\
\text { cerros }\end{array}$ & $\begin{array}{l}\text { cerros y } \\
\text { cañadas }\end{array}$ & $\begin{array}{l}\text { planos, } \\
\text { lomeríos, } \\
\text { cañadas y } \\
\text { cerros }\end{array}$ & $\begin{array}{l}\text { cerros y } \\
\text { cañadas }\end{array}$ & cerros \\
\hline Altitud (m) & $500-600$ & $500-700$ & $100-600$ & $535-650$ & 100 \\
\hline Pendiente (\%) & $6,5-40$ & $33,5-37,5$ & $6,5-31$ & $30-40$ & 25 \\
\hline Rocosidad (\%) & $10-40$ & $10-20$ & $2-25$ & $12,5-17,5$ & 17,5 \\
\hline $\begin{array}{l}\text { Pedregosidad } \\
(\%)\end{array}$ & $0-37,5$ & $0-30$ & $7,5-40$ & $5-16$ & 40 \\
\hline $\begin{array}{l}\text { Profundidad del } \\
\text { suelo }(\mathrm{cm})\end{array}$ & $12,5-50$ & $25-50$ & $25-75$ & $12,5-75$ & 50 \\
\hline $\begin{array}{l}\text { Capacidad de } \\
\text { almacenamiento } \\
\text { de agua en el } \\
\text { suelo }(\mathrm{mm})\end{array}$ & $44-110$ & $24-37$ & $37-125$ & $62-71,5$ & 69 \\
\hline $\mathrm{pH}$ del suelo & $5,5-6,5$ & $5,0-6,7$ & $5,5-6,8$ & $5,5-6,6$ & 6,7 \\
\hline $\begin{array}{l}\text { Precipitación } \\
\text { media }(\mathrm{mm})\end{array}$ & $800-1075$ & $1234-1368$ & $1200-1496$ & $1500-1550$ & 760 \\
\hline $\begin{array}{l}\text { Temporada de } \\
\text { lluvias (días) }\end{array}$ & $147-152$ & $139-171$ & $128-188$ & $155-171$ & 121 \\
\hline $\begin{array}{l}\text { Periodo de } \\
\text { crecimiento } \\
\text { vegetal (días) }\end{array}$ & $171-195$ & $168-182$ & $157-215$ & $180-199$ & 142 \\
\hline $\begin{array}{l}\text { Temperatura } \\
\text { media }\left({ }^{\circ} \mathrm{C}\right)\end{array}$ & $23-26$ & $23-25,5$ & $23-24,7$ & $24-26$ & 25 \\
\hline $\begin{array}{l}\text { Especies } \\
\text { características }\end{array}$ & $\begin{array}{l}\text { E. cyclocarpum } \\
\text { T. rosea } \\
\text { B. simaruba }\end{array}$ & $\begin{array}{l}\text { C. pentandra } \\
\text { L. arborea } \\
\text { B. arborea }\end{array}$ & $\begin{array}{l}\text { E. cyclocarpum } \\
\text { T. crysantha } \\
\text { T. rosea }\end{array}$ & $\begin{array}{l}\text { A. graveolens } \\
\text { E. cyclocarpum } \\
\text { B. alicastrum }\end{array}$ & $\begin{array}{l}\text { C. sclerocarpa, } \\
\text { S. cirrhata }\end{array}$ \\
\hline $\begin{array}{l}\text { Índice promedio } \\
\text { de diferenciación } \\
\text { de diversidad } \\
\text { entre sitios }\end{array}$ & 0,49 & 0,57 & 0,66 & 0,63 & --- \\
\hline $\begin{array}{l}\text { Índice promedio } \\
\text { de similitud } \\
\text { florística entre } \\
\text { sitios }\end{array}$ & 40,8 & 28,9 & 21,0 & 22,7 & --- \\
\hline $\begin{array}{l}\text { No. de especies } \\
\text { arbóreas } \\
\text { registradas }\end{array}$ & 21 & 25 & 43 & 29 & 8 \\
\hline
\end{tabular}


Tabla 2 (cont...). Características ecológicas de las zonas con Brosimum alicastrum Sw. en la costa del Océano Pacífico por tipo de vegetación

\begin{tabular}{|c|c|c|c|}
\hline \multirow{2}{*}{ Característica } & \multicolumn{3}{|c|}{ Selva alta perennifolia } \\
\hline & Zona 12 & Zona 13 & Zona 14 \\
\hline $\begin{array}{l}\text { Localización: } \\
\text { Entidad y No. de } \\
\text { sitio }\end{array}$ & $\begin{array}{l}\text { Chiapas } \\
\text { (1) }\end{array}$ & $\begin{array}{l}\text { Chiapas } \\
\text { (2) }\end{array}$ & $\begin{array}{l}\text { Chiapas } \\
\text { (3) }\end{array}$ \\
\hline Superficie (ha) & 128000 & 456500 & 327900 \\
\hline Fisiografía & planos costeros & cerros & cerros \\
\hline Altitud (m) & $70-140$ & $200-1500$ & $140-1800$ \\
\hline Pendiente (\%) & $1-2$ & $35-80$ & $30-74$ \\
\hline Rocosidad (\%) & 2 & $16-90$ & $40-60$ \\
\hline $\begin{array}{l}\text { Pedregosidad } \\
(\%)\end{array}$ & 1 & $10-25$ & 10 \\
\hline $\begin{array}{l}\text { Profundidad del } \\
\text { suelo }(\mathrm{cm})\end{array}$ & 200 & 50 & 80 \\
\hline $\begin{array}{l}\text { Capacidad de } \\
\text { almacenamiento } \\
\text { de agua en el } \\
\text { suelo }(\mathrm{mm})\end{array}$ & $144-332$ & 88 & 112 \\
\hline $\mathrm{pH}$ del suelo & 5,5 & $5,0-6,5$ & $5,0-6,5$ \\
\hline $\begin{array}{l}\text { Precipitación } \\
\text { media }(\mathrm{mm})\end{array}$ & 3000 & 1750 & 4500 \\
\hline $\begin{array}{l}\text { Temporada de } \\
\text { lluvias (días) }\end{array}$ & $200-244$ & 217 & 233 \\
\hline $\begin{array}{l}\text { Periodo de } \\
\text { crecimiento } \\
\text { vegetal (días) }\end{array}$ & 312 & 245 & 265 \\
\hline $\begin{array}{l}\text { Temperatura } \\
\text { media }\left({ }^{\circ} \mathrm{C}\right)\end{array}$ & 25,7 & 21,5 & $23,6-27,7$ \\
\hline $\begin{array}{l}\text { Especies } \\
\text { características }\end{array}$ & $\begin{array}{l}\text { T. amazonia } \\
\text { V. guatemalensis }\end{array}$ & $\begin{array}{l}\text { A. zapota } \\
\text { B. flamea } \\
\text { Z. integerrima }\end{array}$ & $\begin{array}{l}\text { T. amazonia } \\
\text { S. mexicana }\end{array}$ \\
\hline $\begin{array}{l}\text { Índice promedio } \\
\text { de diferenciación } \\
\text { de diversidad } \\
\text { entre sitios }\end{array}$ & --- & --- & --- \\
\hline $\begin{array}{l}\text { Índice promedio } \\
\text { de similitud } \\
\text { florística entre } \\
\text { sitios }\end{array}$ & --- & --- & --- \\
\hline $\begin{array}{l}\text { No. de especies } \\
\text { arbóreas } \\
\text { registradas }\end{array}$ & --- & 12 & 17 \\
\hline
\end{tabular}


Tabla 2 (cont...). Características ecológicas de las zonas con Brosimum alicastrum Sw. en la costa del Océano Pacífico por tipo de vegetación

\begin{tabular}{|c|c|c|c|c|}
\hline \multirow{2}{*}{ Característica } & \multicolumn{4}{|c|}{ Selva alta subcaducifolia } \\
\hline & Zona 15 & Zona 16 & Zona 17 & Zona 18 \\
\hline $\begin{array}{l}\text { Localización: } \\
\text { Entidad y No. de } \\
\text { sitio }\end{array}$ & Chiapas (1) & Chiapas (2) & Chiapas (3) & Oaxaca (4 y 5) \\
\hline Superficie (ha) & 261000 & No determinada & No determinada & 72601 \\
\hline Fisiografía & $\begin{array}{c}\text { planos y vegas de } \\
\text { río }\end{array}$ & vegas de río & $\begin{array}{l}\text { laderas y } \\
\text { barrancas }\end{array}$ & $\begin{array}{l}\text { planos y } \\
\text { lomeríos }\end{array}$ \\
\hline Altitud (m) & $20-200$ & $450-700$ & $500-800$ & $69-105$ \\
\hline Pendiente (\%) & $1-5$ & $1-4$ & $15-75$ & $5-10$ \\
\hline Rocosidad (\%) & 5 & 2 & $<35$ & $5-20$ \\
\hline $\begin{array}{l}\text { Pedregosidad } \\
(\%)\end{array}$ & 3 & 1 & $>15$ & $3-35$ \\
\hline $\begin{array}{l}\text { Profundidad del } \\
\text { suelo }(\mathrm{cm})\end{array}$ & 200 & 200 & 25 & $100-200$ \\
\hline $\begin{array}{l}\text { Capacidad de } \\
\text { almacenamiento } \\
\text { de agua en el } \\
\text { suelo }(\mathrm{mm})\end{array}$ & 126 & 120 & 33 & $140-146$ \\
\hline pH del suelo & 5,3 & $5,0-6,5$ & 6,7 & $5,3-7,25$ \\
\hline $\begin{array}{l}\text { Precipitación } \\
\text { media }(\mathrm{mm})\end{array}$ & 2100 & 2000 & $800-2294$ & 1350 \\
\hline $\begin{array}{l}\text { Temporada de } \\
\text { lluvias (días) }\end{array}$ & 196 & 186 & 217 & 185 \\
\hline $\begin{array}{l}\text { Periodo de } \\
\text { crecimiento } \\
\text { vegetal (días) }\end{array}$ & 233 & 221 & 224 & $205-224$ \\
\hline $\begin{array}{l}\text { Temperatura } \\
\text { media }\left({ }^{\circ} \mathrm{C}\right)\end{array}$ & 27,0 & 25 & $22,7-24,2$ & 25 \\
\hline $\begin{array}{l}\text { Especies } \\
\text { características }\end{array}$ & $\begin{array}{l}\text { E. cyclocarpum } \\
\text { L. arborea } \\
\text { T. pentaphylla }\end{array}$ & $\begin{array}{l}\text { E. cyclocarpum } \\
\text { L. arborea } \\
\text { H. courbaril }\end{array}$ & $\begin{array}{l}\text { C. candidissimum } \\
\text { B. persimilis }\end{array}$ & $\begin{array}{l}\text { E.cyclocarpum } \\
\text { L. arborea } \\
\text { H. courbaril }\end{array}$ \\
\hline $\begin{array}{l}\text { Índice promedio } \\
\text { de diferenciación } \\
\text { de diversidad } \\
\text { entre sitios }\end{array}$ & --- & --- & --- & 0,15 \\
\hline $\begin{array}{l}\text { Índice promedio } \\
\text { de similitud } \\
\text { florística entre } \\
\text { sitios }\end{array}$ & --- & --- & --- & 72,7 \\
\hline $\begin{array}{l}\text { No. de especies } \\
\text { arbóreas } \\
\text { registradas }\end{array}$ & 35 & 34 & 33 & 22 \\
\hline
\end{tabular}


Tabla 2 (cont...). Características ecológicas de las zonas con Brosimum alicastrum Sw. en la costa del Océano Pacífico por tipo de vegetación

\begin{tabular}{|c|c|c|c|c|}
\hline \multirow{2}{*}{ Característica } & \multicolumn{4}{|c|}{ Palmar } \\
\hline & Zona 19 & Zona 20 & Zona 21 & Zona 22 \\
\hline $\begin{array}{l}\text { Localización: } \\
\text { Entidad y No. de } \\
\text { sitio }\end{array}$ & $\begin{array}{c}\text { Jalisco (5), } \\
\text { Guerrero (2) } \\
\text { Colima y } \\
\text { Michoacán (1) }\end{array}$ & $\begin{array}{c}\text { Oaxaca } \\
(8 \text { y } 9)\end{array}$ & $\begin{array}{c}\text { Nayarit (6 y } 7) \text {, } \\
\text { Guerrero (4) }\end{array}$ & Guerrero (3) \\
\hline Superficie (ha) & 51576 & 56884 & 42320 & 7514 \\
\hline Fisiografía & planos & planos & $\begin{array}{l}\text { planos, } \\
\text { lomeríos y } \\
\text { cañadas }\end{array}$ & planos aluviales \\
\hline Altitud (m) & $56-100$ & $0-150$ & $0-126$ & 150 \\
\hline Pendiente (\%) & $2-7$ & $0-3$ & $5-15.5$ & $8-10$ \\
\hline Rocosidad (\%) & $0-30$ & $0-10$ & $10-30$ & \\
\hline $\begin{array}{l}\text { Pedregosidad } \\
(\%)\end{array}$ & 0 & 0 & $0-5$ & \\
\hline $\begin{array}{l}\text { Profundidad del } \\
\text { suelo }(\mathrm{cm})\end{array}$ & $50-100$ & 100 & $75-100$ & 75 \\
\hline $\begin{array}{l}\text { Capacidad de } \\
\text { almacenamiento } \\
\text { de agua en el } \\
\text { suelo }(\mathrm{mm})\end{array}$ & $80-160$ & $115-175$ & $98-105$ & 106 \\
\hline $\mathrm{pH}$ del suelo & $6,2-6,8$ & $5,9-7,7$ & $6,6-6,8$ & 6,5 \\
\hline $\begin{array}{l}\text { Precipitación } \\
\text { media }(\mathrm{mm})\end{array}$ & 1000 & $1200-1250$ & $1200-1500$ & 1200 \\
\hline $\begin{array}{l}\text { Temporada de } \\
\text { lluvias (días) }\end{array}$ & $144-156$ & $162-189$ & $163-176$ & 144 \\
\hline $\begin{array}{l}\text { Periodo de } \\
\text { crecimiento } \\
\text { vegetal (días) }\end{array}$ & $180-209$ & $216-220$ & $185-201$ & 193 \\
\hline $\begin{array}{l}\text { Temperatura } \\
\text { media }\left({ }^{\circ} \mathrm{C}\right)\end{array}$ & $25,5-26,0$ & $24-27$ & $24-26$ & 24 \\
\hline $\begin{array}{l}\text { Especies } \\
\text { características }\end{array}$ & $\begin{array}{l}\text { O. guacuyule } \\
\text { E. cyclocarpum } \\
\text { B. simaruba }\end{array}$ & $\begin{array}{l}\text { O. guacuyule } \\
\text { C. pentandra } \\
\text { S. mexicana }\end{array}$ & $\begin{array}{l}\text { O. guacuyule } \\
\text { B. simaruba } \\
\text { Ficus spp. }\end{array}$ & $\begin{array}{l}\text { O. guacuyule } \\
\text { F. glaucescens } \\
\text { C. elastica }\end{array}$ \\
\hline $\begin{array}{l}\text { Índice promedio } \\
\text { de diferenciación } \\
\text { de diversidad } \\
\text { entre sitios }\end{array}$ & 0,59 & 0,889 & 0,59 & --- \\
\hline $\begin{array}{l}\text { Índice promedio } \\
\text { de similitud } \\
\text { florística entre } \\
\text { sitios }\end{array}$ & 25,5 & 12,5 & 25,4 & --- \\
\hline $\begin{array}{l}\text { No. de especies } \\
\text { arbóreas } \\
\text { registradas }\end{array}$ & 19 & 15 & 21 & 11 \\
\hline
\end{tabular}




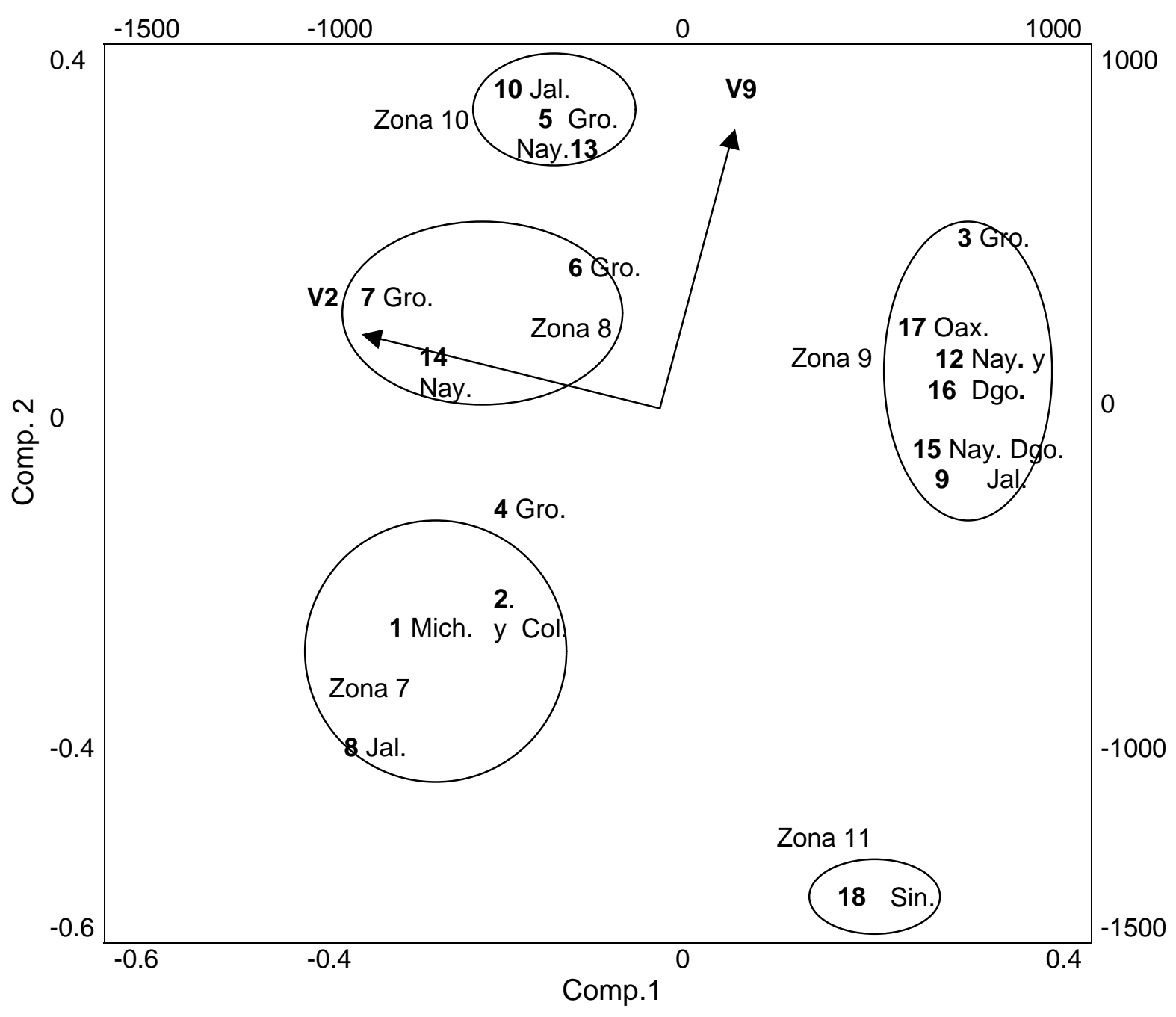

\begin{tabular}{ccc}
\hline $\begin{array}{c}\text { Componente } \\
\text { principal }\end{array}$ & $\begin{array}{c}\text { Importancia } \\
\text { relativa }\end{array}$ & Combinación lineal * \\
\hline 1 & 0,516 & $Y_{1}=-0,970$ V2 + 0,228 V9 \\
\hline 2 & 0,985 & $Y_{2}=0,230$ V2 +- 0,970 V9 \\
\hline
\end{tabular}

*V2,altitud; y V9, precipitación.

Figura 4. Agrupamiento en zonas ecológicas de los diferentes sitios de selvas medianas subcaducifolias en la costa del Océano Pacífico.

Sitios de los estados de: Michoacán y Colima (1 y 2), Guerrero (3 - 7), Jalisco (8 - 10), Nayarit y Durango(11 - 15), Oaxaca (16 - 17) y Sinaloa (18) (Tabla 2 y Fig. 2) 
El 97,6\% de la superficie que ocupa la selva mediana subcaducifolia se encuentra por abajo de los $600 \mathrm{msnm}$ y su límite superior marca la zona de transición entre la zona tropical y templada en la vertiente del Océano Pacifico (COTECOCA, 1975; 1979a, b, c). Así mismo, el 84,1 \% de la superficie que ocupan las zonas con Brosimum alicastrum en este tipo de vegetación se encuentra entre las isoyetas de $1000 \mathrm{~mm}$ a $1400 \mathrm{~mm}$ anuales. Es común que algunas de estas zonas ecológicas se encuentren en lugares más lluviosos que las selvas medianas subperennifolias, especialmente en las laderas de sierras expuestas a vientos húmedos provenientes del mar; sin embargo, una mayor precipitación en estos lugares no parece mejorar las condiciones del sitio, ni la abundancia y posible desarrollo de Brosimum alicastrum (Tabla 1).

Se considera que lo anterior puede ser consecuencia de que las lluvias, aunque más abundantes, están concentradas en pocos meses y los suelos, por ser delgados y de texturas gruesas, no pueden almacenar suficiente cantidad de agua para ser utilizada una vez que concluye el temporal. Además, debido a que estos lugares se localizan a una mayor altitud, presentan una menor temperatura ambiente, lo cual pudiera también influir en la adaptación y desarrollo de Brosimum alicastrum.

Selva alta perennifolia. En la figura 5 se encuentra el diagrama de dispersión de componentes principales, en donde se agrupan los diferentes sitios de este tipo de vegetación en tres zonas ecológicas. Se observa que con dos componentes principales se explica el $100 \%$ de la variabilidad total de este tipo de vegetación y que los coeficientes de las variables altitud (V2) y, en menor grado, la capacidad de almacenamiento de agua en el suelo (V7), así como la profundidad del mismo (V6), son los que contribuyen a esta proporción de la variabilidad. La figura 2 muestra la ubicación de los sitios evaluados.
En la Tabla 2 se describen las principales características de las zonas ecológicas de Brosimum alicastrum, agrupadas con base en el diagrama de la figura 5 (componentes principales), para la selva alta perennifolia, la cual, de acuerdo con los estudios realizados por COTECOCA (1972), presentó una superficie de 912 400 hectáreas en la vertiente del Océano Pacífico y se localiza en la Sierra Madre de Chiapas (Figura 2).

La densidad de Brosimum alicastrum puede considerarse como moderada en la selva alta perennifolia (Tabla 1) y, de acuerdo con información proporcionada por Zenón Abarca (2002), esta especie puede ser más abundante en cerros pedregosos con suelos delgados de origen calcáreo. Aunque de carácter estacional, la precipitación media anual en la selva alta perennifolia es la más alta de los grupos de selva estudiados y la que presenta una mayor amplitud de variación (Tabla 2).

El $86 \%$ de la superficie que ocupa este tipo de vegetación se encuentra localizada entre los 800 y 1800 msnm, una distribución altitudinal poco común, en virtud de que en esa región la isoterma mínima extrema de $0{ }^{\circ} \mathrm{C}$ se encuentra cercana a los 1700 msnm (Rzedowski, 1981); sin embargo, las temperaturas media anual y del mes más frío son superiores a los $21,5^{\circ} \mathrm{C}$ y $18^{\circ} \mathrm{C}$, respectivamente, situándose dentro del límite climatológico de las zonas tropicales húmedas en México (Vega, 1989).

Selva alta subcaducifolia. En la figura 6 se muestra el diagrama de dispersión de componentes principales, en donde se agrupan los sitios que componen a este tipo de vegetación en cuatro zonas ecológicas. Se observa que con dos componentes principales se explica el $98 \%$ de la variabilidad global de este tipo de vegetación y que los coeficientes de las variables altitud (V2) y precipitación (V9), son los que contribuyen en gran medida a explicar tal proporción de la variabilidad. 


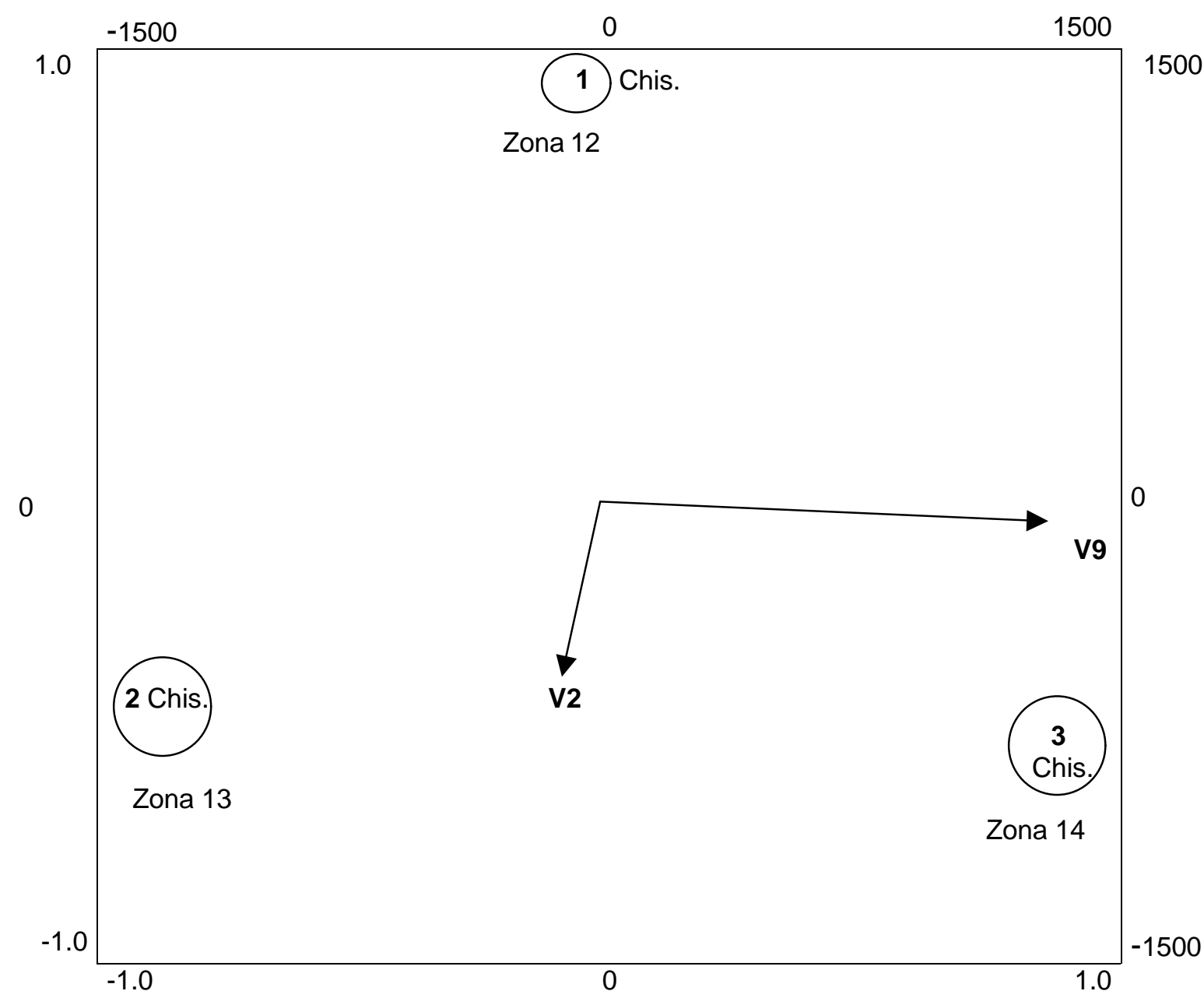

Comp. 1

\begin{tabular}{ccl}
\hline $\begin{array}{c}\text { Componente } \\
\text { principal }\end{array}$ & $\begin{array}{c}\text { Importancia } \\
\text { relativa }\end{array}$ & \multicolumn{1}{c}{ Combinación lineal * } \\
\hline 1 & 0,847 & $Y_{1}=0,997 \mathrm{~V} 2$ \\
\hline 2 & 1,0 & $Y_{2}=-0,968 \mathrm{~V} 2+0,133 \mathrm{~V} 6+-0,177 \mathrm{V7}$ \\
\hline
\end{tabular}

V2, altitud; V6, profundidad de suelo; V7, capacidad de almacenamiento de agua en el suelo

Figura 5. Agrupamiento en zonas ecológicas de los diferentes sitios de selva alta perennifolia en la costa del Océano Pacífico.

Sitios en el estado de Chiapas (1 - 3) (Tabla 2 y Fig. 2) 


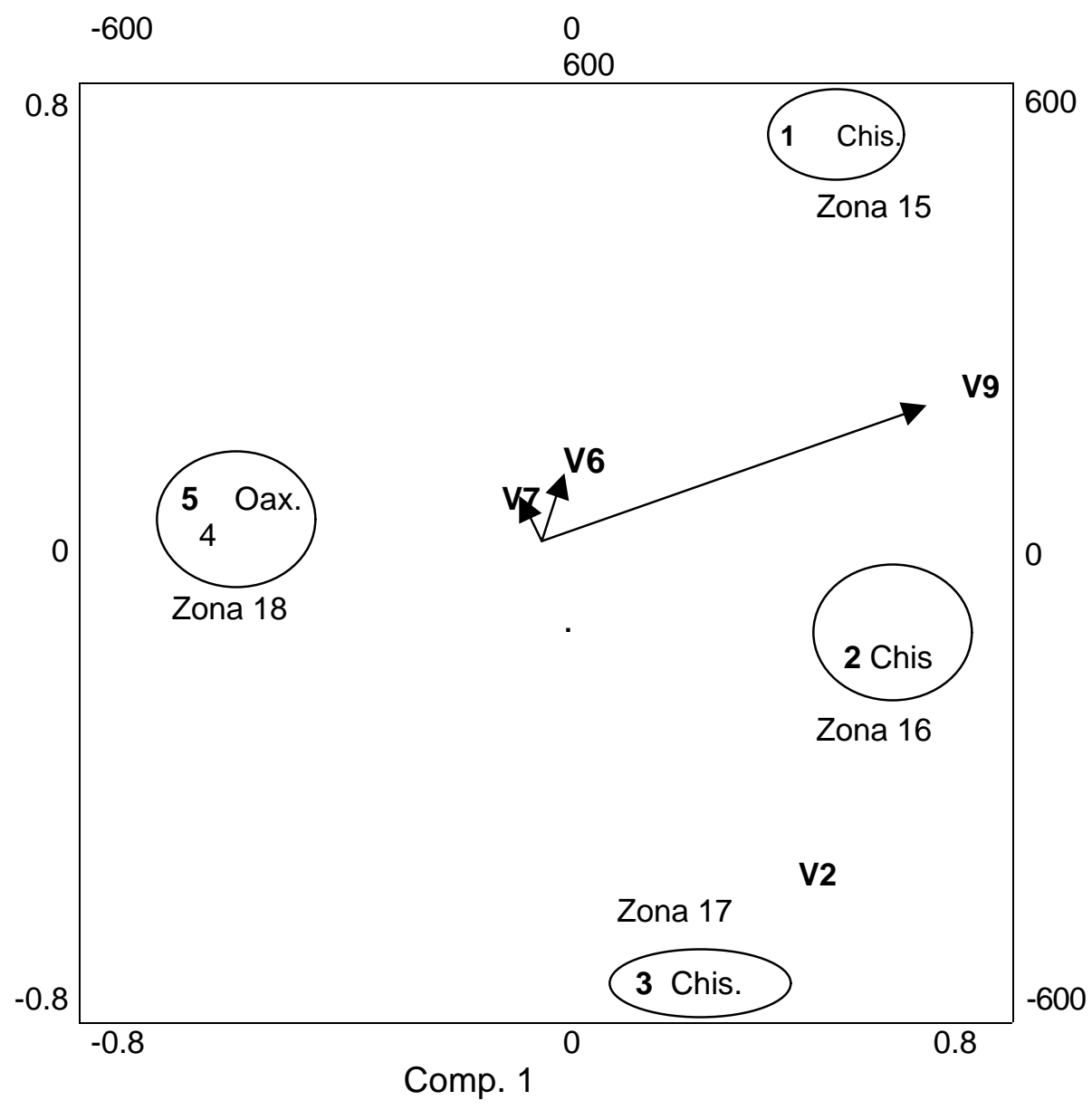

\begin{tabular}{ccl}
\hline $\begin{array}{c}\text { Componente } \\
\text { principal }\end{array}$ & $\begin{array}{c}\text { Importancia } \\
\text { relativa }\end{array}$ & \multicolumn{1}{c}{ Combinación lineal $^{*}$} \\
\hline 1 & 0,671 & $Y_{1}=0,485 \mathrm{~V} 2+0,872 \mathrm{~V} 9$ \\
\hline 2 & 0,980 & $Y_{2}=-0,845 \mathrm{~V} 2+0,220 \mathrm{~V} 6+-0,128 \mathrm{~V} 7+0,468 \mathrm{~V} 9$ \\
\hline
\end{tabular}

$\mathrm{V}$ 2, altitud; V6, profundidad de suelo; V7, capacidad de almacenamiento de agua en el suelo; V9, precipitación.

Figura 6. Agrupamiento en zonas ecológicas de los diferentes sitios de selva alta subcaducifolia en la costa del Océano Pacífico.

Sitios en los estados de: Chiapas (1 - 3) y Oaxaca (4 y 5) (Tabla 2 y Fig. 2) 
La figura 2 indica la distribución de los sitios evaluados.

El la Tabla 2 se describen las principales características de las zonas ecológicas donde existe Brosimum alicastrum, agrupadas con base en el diagrama de la figura 6 (componentes principales), para la selva alta subcaducifolia. En gran parte de la superficie que ocupa, este tipo de vegetación se localiza a menos de 200 msnm, colindando en su limite altitudinal inferior con los manglares y las selvas bajas caducifolia y caducifolia espinosa y, en el superior, con la selva alta perennifolia (COTECOCA, 1972 y 1980b).

La selva alta subcaducifolia se encuentra en áreas de transición con climas cálido subhúmedos a húmedos, es fisonómicamente similar a la selva alta perennifolia en la época de lluvias y gran parte de sus especies arbóreas son caducifolias en la época seca; prospera principalmente en suelos de buena calidad en la llanura costera, pero estos poseen una baja capacidad de retención de agua debido a su textura arenosa, situación que puede afectar la abundancia de Brosimum alicastrum en este tipo de vegetación.

Palmar. En la figura 7 se encuentra el diagrama de dispersión de componentes principales, en donde se agruparon los sitios que componen este tipo de vegetación en cuatro zonas ecológicas. Se aprecia que con dos componentes se explica el 99,4\% de la variabilidad total de esta comunidad vegetal y que los coeficientes de las variables precipitación (V6), capacidad de almacenamiento de agua en el suelo (V4) y, en menor grado, pedregosidad (V3), son los que contribuyen a explicar en mayor medida dicha proporción de la variabilidad. La figura 2 muestra la disposición de los sitios estudiados.

En la Tabla 2 se describen las principales características de las zonas ecológicas de los palmares en donde existe Brosimum alicastrum, agrupadas con base en el diagrama de la figura 7 (componentes principales). De acuerdo con estudios realizados por la COTECOCA (1979a, b; 1980a, b, c), este tipo de vegetación colinda con el manglar y las selvas baja caducifolia y medianas subcaducifolia y subperennifolia.

Gran parte de los palmares donde existe Brosimum alicastrum en la costa del Pacífico mexicano se encuentran en planicies $y$, en menor cantidad, en cañadas y lomeríos. En la Tabla 2 se observa que existe una clara diferenciación, en cuanto a precipitación y variables del suelo (capacidad de almacenamiento de agua, porcentaje de pedregosidad), de las zonas ecológicas determinadas en la figura 7. Este tipo de vegetación es el que mostró una mayor variación explicada por características del suelo, lo cual apoya la idea de considerar a los palmares como un clímax edáfico, según lo menciona COTECOCA (1979a, b; 1980a, b, c).

Las zonas de palmares con presencia de Brosimum alicastrum tienen una diferenciación de diversidad de especies arbóreas de moderada a alta entre sitios y una baja similitud florística entre los mismos. Así mismo, los palmares mostraron la más baja densidad de individuos de la especie de interés (menos de cuatro árboles por hectárea), ya que por lo general esta especie se encuentra en los ecotonos con las selvas medianas subperennifolia y subcaducifolia (Castro Sandoval, 2002 y González Quintero, 2002).

\section{Relación de factores ambientales con atributos dasométricos}

No obstante que Brosimum alicastrum es, generalmente, una especie componente de selvas húmedas, ésta tiene un amplio espectro ecológico y prospera en sitios que proporcionen un mínimo de satisfactores de crecimiento, principalmente de tipo climático. Esta especie parece ser tolerante a restricciones en el suelo (altos niveles de pedregosidad, rocosidad y carbonato de calcio) y a una escasa apertura del dosel (Pennington y 


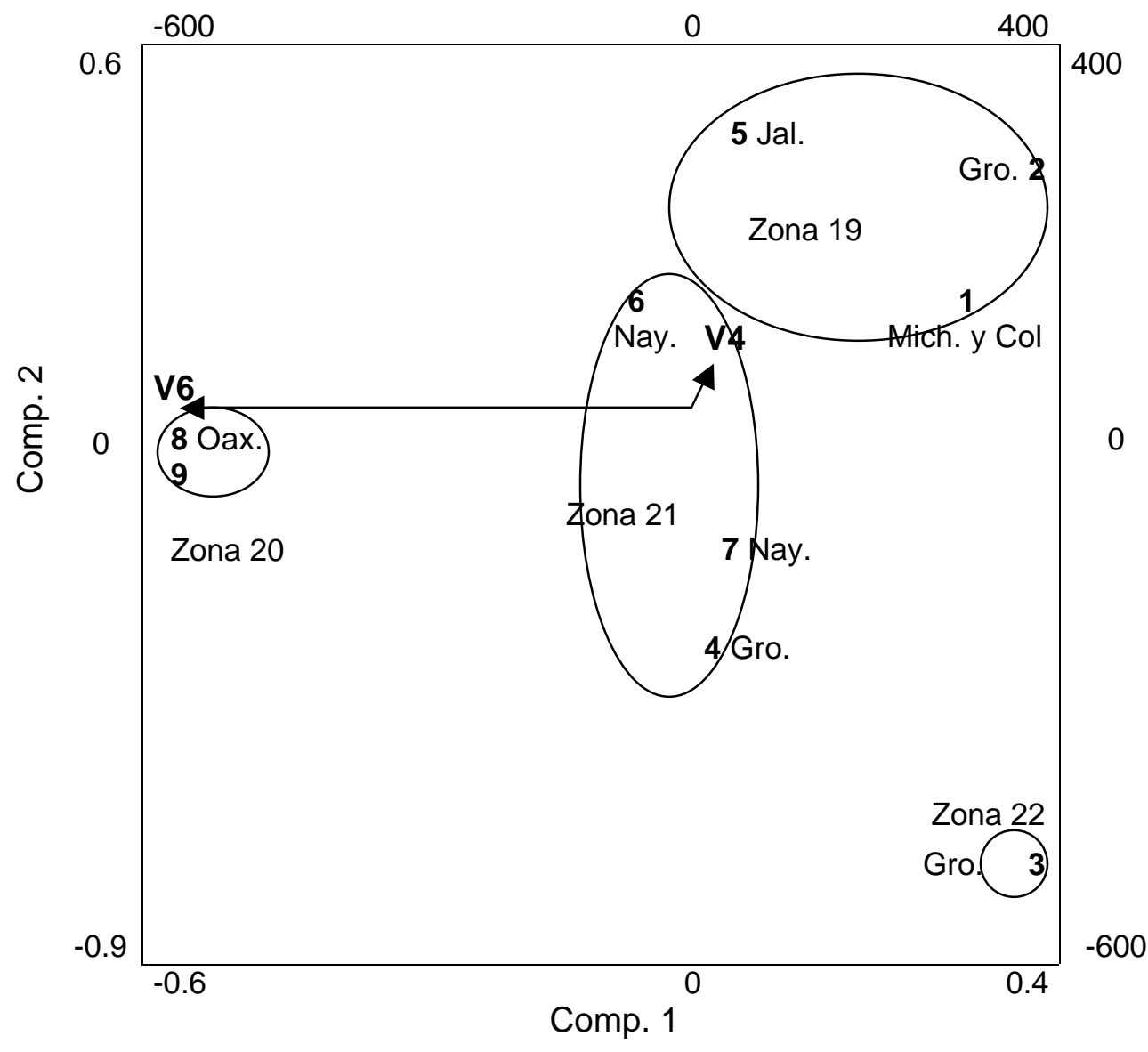

\begin{tabular}{ccc}
\hline $\begin{array}{c}\text { Componente } \\
\text { principal }\end{array}$ & $\begin{array}{c}\text { Importancia } \\
\text { relativa }\end{array}$ & Combinación lineal * \\
\hline 1 & 0,978 & $Y_{1}=-0,999 \mathrm{~V} 6$ \\
\hline 2 & 0,994 & $Y_{2}=0,314 \mathrm{V3}+0,874 \mathrm{~V} 4+0,363 \mathrm{~V} 8$ \\
\hline
\end{tabular}

*V3, pedregosidad, V4, capacidad de almacenamiento de agua en el suelo; V6, precipitación; V8, periodo de crecimiento vegetal.

Figura 7. Agrupamiento en zonas ecológicas de los diferentes sitios de palmar en la costa del Océano Pacífico.

Sitios de los estados de: Michoacán y Colima (1), Guerrero (2 - 4), Jalisco (5), Nayarit (6 y 7) y Oaxaca (8 y 9) (Tabla 2 y Fig. 2.) 
Sarukhán 1968; Pardo y Sánchez 1980; López 1982; Negreros y Mize 1993).

La cantidad de árboles perennifolios en las comunidades vegetales es una variable que, de acuerdo con Vega (1989), se considera un buen indicador del grado de restricción ambiental existente. En el sistema de clasificación de la vegetación propuesto por Miranda y Hernández (1985) para México, el porcentaje de árboles que tiran su hoja durante la época seca del año determina el nombre del tipo de vegetación en que se encuentran.

En este trabajo (Fig. 1 y 4 a 7 ), la precipitación y la altitud fueron las variables que contribuyeron en mayor medida a la agrupación de sitios con presencia de Brosimum alicastrum en diferentes zonas ecológicas. Este resultado coincide, en parte, con lo reportado por Vega (1989), quien señala que la precipitación es el factor más importante para definir el tipo de selva y su distribución en el país (Tabla 3), y quien encontró una correlación positiva $(R=0,7)$ entre la precipitación y la cantidad de árboles perennifolios.

Aunque en la costa del Pacífico se aprecia una tendencia similar entre el porcentaje de árboles perennifolios y la precipitación (Tabla 4), no existen diferencias significativas $(p>0,05)$ de esta última entre las selvas medianas subcaducifolia y subperennifolia. Debido a su presencia en terrenos topográficamente más expuestos a vientos húmedos, como se aprecia en la figura 3 , es probable que una gran parte de la superficie ocupada por selva mediana subcaducifolia en el Pacífico mexicano reciba una mayor precipitación. Esto, sin embargo, no puede afirmarse con exactitud, ya que en el presente trabajo se utilizó la precipitación promedio y no la ponderada para cada sitio.

La costa del Pacífico presenta las condiciones más secas en el país donde prospera la selva mediana subperennifolia con presencia de Brosimum alicastrum, ya que su precipitación promedio es inferior a la media nacional para este tipo de vegetación (Tablas 3 y 4). En contraste, la costa del Pacífico posee las condiciones más húmedas de México para la selva mediana subcaducifolia donde se encuentra esta especie, debido a que su precipitación promedio en este tipo de vegetación es superior a la media nacional (Tablas 3 y 4 ).

De acuerdo con la Tabla 4, en la costa del Pacífico no existen diferencias significativas de precipitación entre las selvas medianas subcaducifolia y subperennifolia; sin embargo, se tienen desigualdades notables entre ambas selvas respecto a la densidad de individuos de Brosimum alicastrum y al porcentaje de árboles perennifolios en la época seca del año. También se presentan diferencias significativas $(p \leq 0,05)$ entre estas selvas con relación a la capacidad de almacenamiento de agua en el suelo y a los periodos de crecimiento vegetal, ambas características con valores superiores en la selva mediana subperennifolia y que explican, en parte, una mayor abundancia de Brosimum alicastrum en este tipo de vegetación.

El diagrama de perfil de la vegetación, representado en la figura 3 , muestra que suelos profundos con gran capacidad de almacenamiento de agua mantienen selvas medianas subperennifolias con una mayor densidad de Brosimum alicastrum; en contraste, suelos delgados con baja capacidad de almacenamiento de agua sustentan selvas medianas subcaducifolias con una menor densidad de esta especie.

En la figura 3 también se observa que las selvas medianas subperennifolias se localizan cerca de fuentes permanentes de agua, en valles y faldas de sierras, donde se almacenan parte de los escurrimientos de las tierras altas. 
Tabla 3. Precipitación media anual en los diferentes tipos de selva de México

\begin{tabular}{lcccc}
\hline & \multicolumn{4}{c}{ TIPO DE SELVA } \\
\cline { 2 - 5 } & Caducifolia & Subcaducifolia & Subperennifolia & Perennifolia \\
\hline $\begin{array}{l}\text { Porcentaje de árboles } \\
\text { perennifolios (época seca) }\end{array}$ & $0-25$ & $26-50$ & $51-75$ & $76-100$ \\
\hline Precipitación $(\mathrm{mm})$ & $945 \mathrm{~d}^{*}$ & $1130 \mathrm{c}$ & $1640 \mathrm{~b}$ & $2509 \mathrm{a}$ \\
\hline Número de observaciones & 177 & 67 & 55 & 40 \\
\hline
\end{tabular}

* Tipos de selva con la misma letra son estadísticamente iguales $(p \leq 0,05)$.

Fuente: Vega (1989).

Tabla 4. Atributos fisonómico-estructurales de la vegetación y características del medio físico en diferentes tipos de selva de la costa del Pacífico mexicano

\begin{tabular}{lcccc}
\hline & \multicolumn{4}{c}{ TIPO DE SELVA } \\
\cline { 2 - 5 } & Caducifolia & Subcaducifolia & Subperennifolia & Perennifolia \\
\hline $\begin{array}{l}\text { Porcentaje de árboles } \\
\text { perennifolios (época } \\
\text { seca) }\end{array}$ & $0-25$ & $26-50$ & $51-75$ & $76-100$ \\
\hline $\begin{array}{l}\text { Arboles de } \\
\text { B. Alicastrum por ha }\end{array}$ & 0 & 16,4 & 64,1 & 20,0 \\
\hline $\begin{array}{l}\text { Precipitación media } \\
\text { anual (mm) }\end{array}$ & $1132,0 \mathrm{c}^{*}$ & $1312,0 \mathrm{~b}$ & $1313,2 \mathrm{~b}$ & $3083,3 \mathrm{a}$ \\
\hline $\begin{array}{l}\text { Capacidad de almacena- } \\
\text { miento de agua en el } \\
\text { suelo (mm) }\end{array}$ & $47,9 \mathrm{bc}$ & $73,1 \mathrm{~b}$ & $179,2 \mathrm{a}$ & $117,2 \mathrm{~b}$ \\
$\begin{array}{l}\text { Periodo de crecimiento } \\
\text { vegetal (días) }\end{array}$ & $143,1 \mathrm{~d}$ & $182,6 \mathrm{c}$ & $223,8 \mathrm{~b}$ & $277,0 \mathrm{a}$ \\
\hline $\begin{array}{l}\text { Número de } \\
\text { observaciones }(\mathrm{n})\end{array}$ & 15 & 34 & 35 & 7 \\
\hline
\end{tabular}

* Tipos de selva con la misma letra son estadísticamente iguales $(p \leq 0,05)$.

Esta situación permite una recarga de agua en el suelo, mejorando su disponibilidad durante el año y favoreciendo el crecimiento de Brosimum alicastrum. Además, los individuos de esta especie encuentran condiciones propicias para su desarrollo en barrancas poco expuestas a vientos secos y a excesiva insolación, debido a que estos lugares conservan la humedad ambiental por más tiempo.

La capacidad de almacenamiento de agua en el suelo en selvas de la costa del Pacífico mexicano con presencia de Brosimum alicastrum, depende principalmente de la profundidad del mismo y, en menor medida, de su capacidad de retención de humedad según su textura (Tabla 5).

No obstante que existe una correlación positiva entre la capacidad de almacenamiento de agua en el suelo y el periodo de crecimiento vegetal para los diferentes tipos de vegetación en donde se encuentra Brosimum alicastrum, el grado de asociación más alto entre dichas variables $\left(R^{2}=0,78\right)$ se calculó para la selva mediana subperennifolia (Fig. 8), en la cual se presentó también la más alta densidad de individuos de esta especie (Tabla 4). 
Tabla 5. Relación de la capacidad de almacenamiento de agua en el suelo con la profundidad y capacidad de retención de agua en el mismo según su textura $(p \leq 0,05)$

\begin{tabular}{|c|c|c|c|}
\hline ECUACIÓN & $\mathrm{R}^{2}$ & $\begin{array}{c}\text { ERROR } \\
\text { ESTÁNDAR }\end{array}$ & $n$ \\
\hline$C A A S=-2,305+1,413 X 1$ & 0,877 & 24,507 & 56 \\
\hline$C A A S=7,875+70,464 X 2$ & 0,098 & 66,374 & 56 \\
\hline$C A A S=-97,18+1,409 X 1+68,886 X 2$ & 0,971 & 12,105 & 56 \\
\hline
\end{tabular}

Finalmente, la densidad de Brosimum alicastrum, al igual que el porcentaje de árboles perennifolios, se incrementaron a medida que aumentaron los periodos de crecimiento vegetal (Tabla 4); sin embargo, en la selva alta perennifolia la densidad de Brosimum alicastrum disminuyó, posiblemente debido a que en este tipo de vegetación existe una gran diversidad de especies arbóreas y la dominancia de sólo una de ellas, es menos frecuente.

Asimismo, tanto la densidad como el área basal de Brosimum alicastrum tuvieron una estrecha relación con la precipitación y el periodo de crecimiento vegetal (Fig. 9), siendo esta relación más alta para la densidad con el periodo de crecimiento vegetal $\left(R^{2}=0,95\right)$ y para el área basal con la precipitación $\left(R^{2}=0,90\right)$.

\section{CONCLUSIONES}

Mediante el análisis de componentes principales, la información biofísica de 55 sitios ubicados en el área de distribución natural de Brosimum alicastrum Sw. en la costa del Pacífico mexicano fue agrupada en 22 zonas ecológicas dentro de cinco tipos de vegetación (selvas mediana subperennifolia, mediana subcaducifolia, alta perennifolia y alta subcaducifolia y palmar); siendo la precipitación y la altitud las variables que contribuyeron en mayor medida a la definición de tales zonas.

Brosimum alicastrum fue más abundante en las selvas medianas subperennifolias que en los otros cuatro tipos de vegetación, debido principalmente a una alta capacidad de almacenamiento de agua en sus suelos $(179 \mathrm{~mm})$ y a sus largos periodos de crecimiento vegetal (224 días). Ambas variables estuvieron estrechamente correlacionadas entre sí $\left(R^{2}=0,78\right)$.

La precipitación y el periodo de crecimiento vegetal fueron las variables mejor relacionadas con la densidad y el área basal de Brosimum alicastrum, particularmente la densidad con el periodo de crecimiento vegetal $\left(R^{2}=0,95\right)$ y el área basal con la precipitación $\left(R^{2}=0,90\right)$.

\section{AGRADECIMIENTOS}

Al Ing. Gregorio Villegas Durán, Director General de COTECOCA, por las facilidades brindadas para la elaboración de este trabajo.

N.E. El Comité Editorial agradece al Ing. Ignacio Salomón Quintana por su apoyo en la edición de las figuras. 

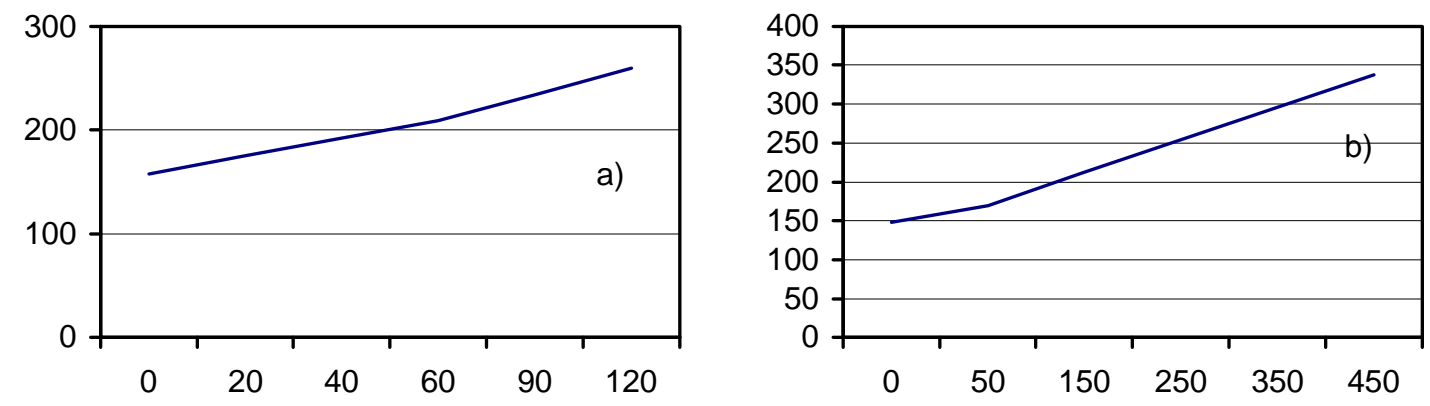

$Y=159,646+0,281 X$

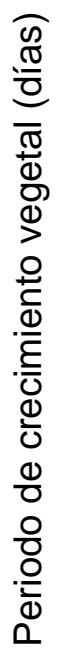

$\mathrm{R}^{2}=0,19 ; p \leq 0,05 ; \mathrm{n}=46$

$Y=148,300+0,422 X$

$\mathrm{R}^{2}=0,78 ; p \leq 0,05 ; \mathrm{n}=51$

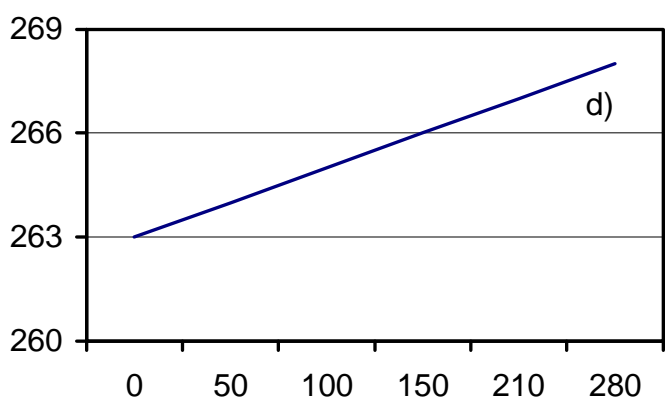

$Y=173,222+0,386 X$

$\mathrm{R}^{2}=0,50 ; p \leq 0,05 ; \mathrm{n}=14$

$Y=263,604+0,017 X$

$\mathrm{R}^{2}=0,07 ; p \leq 0,05 ; \mathrm{n}=8$

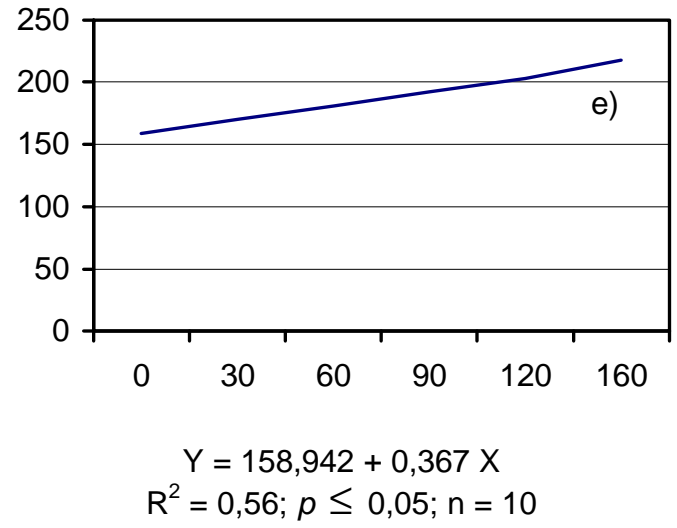

Capacidad de almacenamiento de aqua en el suelo $(\mathrm{mm})$

Figura 8. Relación entre el periodo de crecimiento vegetal (días) y la capacidad de almacenamiento de agua en el suelo $(\mathrm{mm})$, para las selvas mediana subcaducifolia (a), mediana subperennifolia (b), alta subcaducifolia (c), alta perennifolia (d) y palmar (e) en la costa del Pacífico mexicano. 

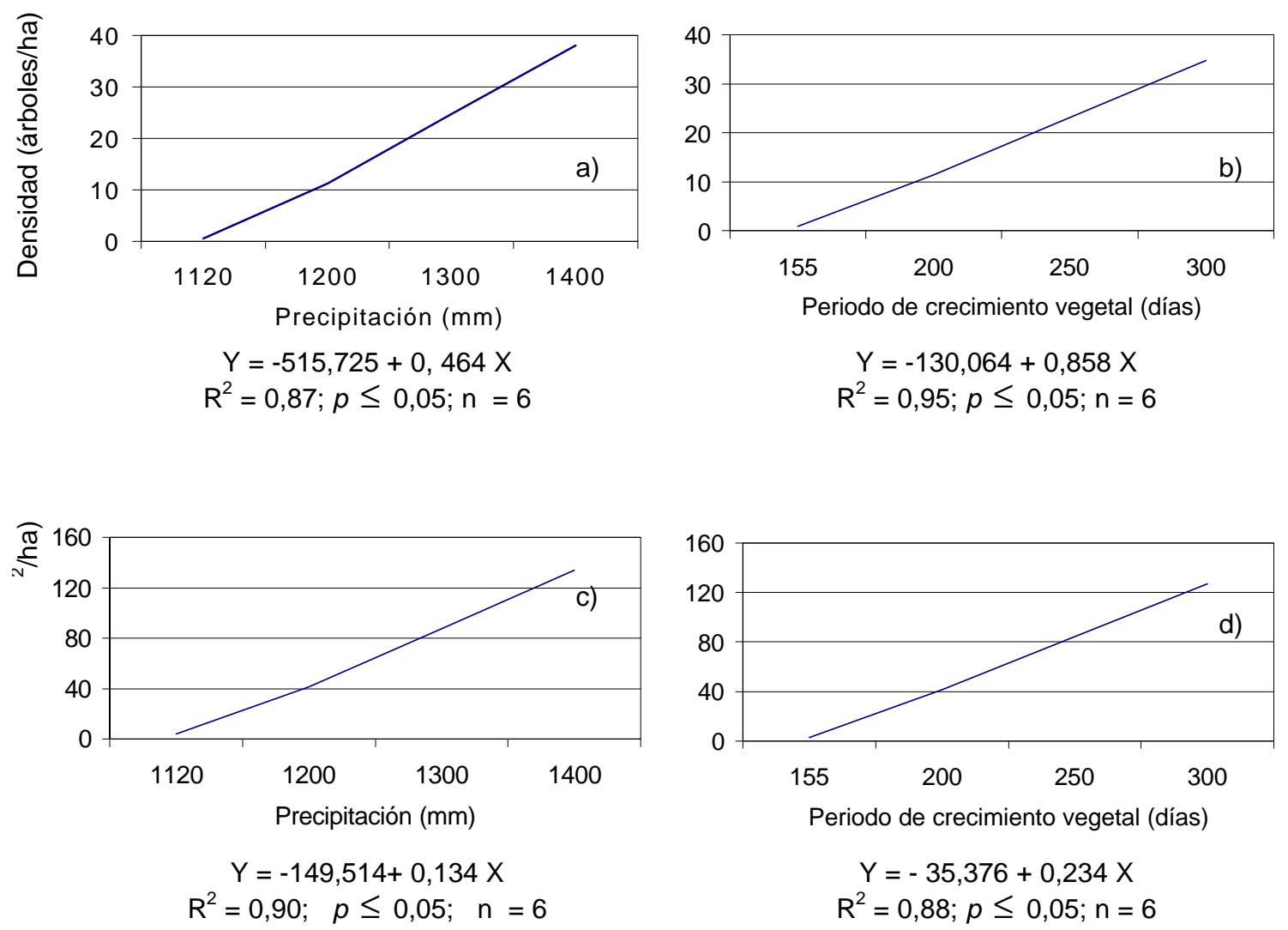

Figura 9. Relación de la densidad de Brosimum alicastrum, con la precipitación media anual (mm) (a) y el período de crecimiento vegetal (días) (b), y de su área basal, con la precipitación media anual $(\mathrm{mm})$ (c) y el período de crecimiento vegetal (días) (d) en la costa del Pacífico mexicano.

\section{REFERENCIAS}

Agrología. 1970. Estudio agrológico detallado no. 59 del estado de Jalisco. SARH. México, D.F. pp:32-40.

Agrología. 1971. Estudio agrológico detallado no. 37 del estado de Oaxaca. SARH. México, D.F. pp:10-20.

Agrología. 1972a. Estudio agrológico detallado no. 38 del estado de Oaxaca. SARH. México, D.F. pp:10-20.

Agrología. 1972b. Estudio agrológico detallado no. 59 del estado de Nayarit. SARH. México, D.F. pp:5- 20.
Agrología. 1973. Estudio agrológico detallado no. 93 del estado de Oaxaca. SARH. México, D.F. pp:10-20.

Agrología. 1974. Estudio agrológico detallado no. 40 del estado de Nayarit. SARH. México, D.F. pp:19-25.

Agrología. 1975a. Estudio agrológico detallado no. 63 del estado de Sinaloa. SARH. México, D.F. pp:10-27.

Agrología. 1975b. Estudio agrológico detallado no. 72 del estado de Jalisco. SARH. México, D.F. pp:30-46.

Agrología. 1975c. Estudio agrológico detallado no. 82 del estado de Nayarit. SARH. México, D.F. pp:10-20. 
Agrología. 1977a. Estudio agrológico detallado no. 174 del estado de Sinaloa. SARH. México, D.F. pp:10-20.

Agrología. 1977b. Estudio agrológico detallado no. 177 del estado de Sinaloa. SARH. México, D.F. pp:17-30.

Agrología. 1979a. Estudio agrológico detallado no. 123 del estado de Jalisco. SARH. México, D.F. pp:30-45.

Agrología. 1979b. Estudio agrológico detallado no. 137 del estado de Jalisco. SARH. México, D.F. pp 30-40.

Castro Sandoval. 2002. Comunicación personal.

COTECOCA. 1972. Memoria regional de Coeficientes de agostadero del estado de Chiapas. Secretaria de Agricultura y Ganadería. México, D.F. 118 p.

COTECOCA. 1975. Memoria regional de Coeficientes de agostadero del estado de Sinaloa. Secretaria de Agricultura y Ganadería. México, D.F. 83 p.

COTECOCA. 1979a. Memoria regional de Coeficientes de agostadero del estado de Jalisco. Secretaria de Agricultura y Recursos Hidráulicos. México, D.F. 163 p.

COTECOCA. 1979b. Memoria regional de Coeficientes de agostadero de los estados de Michoacán y Colima. Secretaria de Agricultura y Recursos Hidráulicos. México, D.F. 161 p.

COTECOCA. 1979c. Memoria regional de Coeficientes de agostadero del estado de Durango. Secretaria de Agricultura y Recursos Hidráulicos. México, D.F. 200 p.

COTECOCA. 1980a. Memoria regional de Coeficientes de agostadero del estado de Guerrero. Secretaria de
Agricultura y Recursos Hidráulicos. México, D.F. 161 p.

COTECOCA. 1980b. Memoria regional de Coeficientes de agostadero del estado de Oaxaca. Secretaria de Agricultura y Recursos Hidráulicos. México, D.F. 306 p.

COTECOCA. 1980c. Memoria regional de Coeficientes de agostadero del estado de Nayarit. Secretaria de Agricultura y Recursos Hidráulicos. México, D.F. 147 p.

Cochran, W.G. y G.M. Cox. 1965. Diseños experimentales. Trillas. México, D.F. $661 \mathrm{p}$.

FAO. 1981. Informe del proyecto de las zonas agroecológicas; metodología y resultados para América del Sur y Central. Vol. 3. Roma. 66 p.

González Quintero. 2002. Comunicación personal.

López, M.L. 1982. Variación del tamaño de las semillas, la germinación y la asignación de energía en plántulas de Brosimum alicastrum Swartz, en Veracruz, México. Tesis de Licenciatura en Biología. Universidad Nacional Autónoma de México. México, D.F. $107 \mathrm{p}$.

Magurran, A. E. 1988. Ecological diversity and its measurement. Croom Helm. Gran Bretaña. 179 p.

Mathsoft Inc. 1999. S-PLUS 2000 professional. Edition for Windows Release. Seattle, Washington, EUA.

Millán, C.A.G. y C.A Ortega. 1999. Programa de manejo forestal del predio "La Quebrada", Tomatlán, Jalisco, México. 88 p.

Miranda, F. y E. Hernández X. 1985. Los tipos de vegetación en México y su clasificación. Xolocotzia Tomo 1. 
Universidad Autónoma Chapingo. Chapingo, México. pp. 41-162.

Negreros C., P. y C. Mize. 1993. Effects of partial overstory removal on the natural regeneration of a tropical forest in Quintana Roo, México. Forest Ecology and Management 58: 259-272.

Ortiz V., B. y C.A Ortiz S. 1990. Edafología. Universidad Autónoma Chapingo. Chapingo, México. 394 p.

Pardo T., E. y M.C. Sánchez. 1980. Brosimum alicastrum (Ramón, Capomo, Ojite, Ojoche), Recurso Silvestre Desaprovechado. $2^{\mathrm{a}} \mathrm{Ed}$. Instituto Nacional de Investigaciones Sobre Recursos Bióticos. Xalapa, Veracruz, México. $31 \mathrm{p}$.

Pennington, T.D. y J. Sarukhán K. 1968. Manual para la identificación de campo de los principales árboles tropicales de México. FAO-Instituto Nacional de Investigaciones Forestales. México, D.F. pp. 122 y 123.
Peters, C.M. 1989. Reproduction, growth and the population dynamics of Brosimum alicastrum Sw. in a moist tropical forest of central Veracruz, Mexico. Ph.D. Dissertation. Yale University. New Haven, EUA. 258 p.

Rzedowski, J. 1981. Vegetación de México. LIMUSA. México, D.F. 432 p.

SPP (Secretaría de Programación y Presupuesto). 1981. Atlas nacional del medio físico. Dirección General de Geografía del Territorio Nacional. México, D.F. 224 p.

Vega L., A. 1989. Metodología para la delimitación de los trópicos húmedo y seco de México por medio de los tipos de vegetación. SARHCOTECOCA. México, D.F. 86 p.

Vega L., A. 1996. Inventario de las plantas forrajeras del Estado de México. SARH, Delegación en el Estado de México. Zinacantepec, México. 30 p.

Zenón Abarca. 2002. Comunicación personal.»

1 Programa Forestal. Colegio de Postgraduados. Km 35.5 Carretera México-Texcoco. Montecillo 56230 Edo. de México. c.e.: adrianvegalopez@yahoo.com.mx, ignaciov@colpos.mx, vicmac@colpos.mx.

Manuscrito recibido el 14 de febrero de 2002.

Aceptado el 23 de septiembre de 2002.

Este documento se debe citar como:

Vega L., A.; J.I. Valdez H y V.M. Cetina A. 2003. Zonas ecológicas de Brosimun alicastrum Sw. en la costa del Pacífico mexicano. Madera y Bosques 9(1):25-53. 